Factor Structure in Commodity Futures Return and Volatility

\author{
Peter Christoffersen, Asger Lunde and Kasper V. Olesen
}

CREATES Research Paper 2014-31 


\title{
Factor Structure in Commodity Futures Return and Volatility*
}

\author{
Peter Christoffersen $^{\mathrm{a}} \quad$ Asger Lunde $^{\mathrm{b}}$ \\ Kasper V. Olesen ${ }^{\mathrm{b}}$ \\ ${ }^{a}$ Rotman School of Management, University of Toronto, CBS \& CREATES \\ ${ }^{b}$ Aarhus University, Department of Economics and Business $\mathcal{E}$ CREATES
}

September 8, 2014

\begin{abstract}
Using data on more than 750 million futures trades during 2004-2013, we analyze eight stylized facts of commodity price and volatility dynamics in the post financialization period. We pay particular attention to the factor structure in returns and volatility and to commodity market integration with the equity market. We find evidence of a factor structure in daily commodity futures returns. However, the factor structure in daily commodity futures volatility is even stronger than in returns. When computing model-free realized commodity betas with the stock market we find that they were high during 2008-2010 but have since returned to the pre-crisis level close to zero. The common factor in commodity volatility is nevertheless clearly related to stock market volatility. We conclude that, while commodity markets appear to again be segmented from the equity market when only returns are considered, commodity volatility indicates a nontrivial degree of market integration.
\end{abstract}

Keywords: Factor structure, financial volatility, beta, high-frequency data, commodities, financialization

JEL Classifications: G13, Q02

*All authors acknowledge support from CREATES - Center for Research in Econometric Analysis of Time Series (DNRF78), funded by the Danish National Research Foundation. Christoffersen was also supported by Bank of Canada, GRI, and the Social Sciences, and Humanities Research Council of Canada. Lunde and Olesen thank the AU Ideas Pilot Center, Stochastic and Econometric Analysis of Commodity Markets, for financial support. Address correspondence to Peter Christoffersen, Rotman School of Management, University of Toronto, 105 St. George St., M5S 3E6 Toronto, Canada; E-mail address: peter.christoffersen@rotman.utoronto.com. 


\section{Introduction}

The deregulation of commodity markets in the early 2000s, and the subsequent large inflows of investment capital to commodity futures and related securities, has sparked a heated debate in the popular press as well as in academia. A large part of the discussion of this so-called "financialization" of commodity markets has focused on bubbles in commodity prices and increases in commodity price volatility supposedly caused by futures market trading. The relationship between commodity futures and other asset markets, and in particular risk sharing across markets, has received substantial attention in academia. Cheng \& Xiong (2013) provide an excellent overview of existing work on the financialization of commodity futures markets.

We use more than 750 million commodity futures transactions to construct daily realized volatility for fifteen commodities during the 2004-2013 period. To our knowledge, we are the first to construct realized covariances for each commodity with the stock market which we use to develop time-varying but model-free stock market betas as well as systematic risk contributions for each commodity. We use these measures along with daily futures returns to address the following research questions:

First, what are the stylized facts of commodity futures returns and volatility post financialization? Second, is there a factor structure in commodity futures returns? Third, is the stock market driving the common component of commodity futures returns? Fourth, do the stock market betas of commodity futures returns vary significantly over time? Fifth, does the ratio of commodity futures return volatility explained by the stock market beta change over time? Sixth, is there a factor structure in commodity futures volatility? Finally, is stock market volatility driving the common component of commodity futures volatility? The stylized facts that we uncover are:

Fact \#1: Daily realized commodity futures volatility has extremely high persistence.

Fact \#2: The logarithm of realized commodity futures volatility is close to normally distributed.

Fact \#3: There is some evidence of a factor structure in daily commodity futures returns excluding meats. 
Fact \#4: The factor structure in daily commodity futures volatility is much stronger than the factor structure in returns.

Fact \#5: There is little evidence of a time-trend in the degree of integration across commodity futures markets during the 2004-2013 period.

Fact \#6: The strong common factor in commodity volatility is largely driven by stock market volatility.

Fact \#7: Commodity betas with the stock market were high during 2008-2010 but have since returned to a level close to zero.

Fact \#8: Commodity futures returns standardized by expected realized volatility are closer to normally distributed than the returns themselves but still display leptokurtosis.

Most authors, including Baker (2014), Baker \& Routledge (2012), and Hamilton \& Wu (2014), date the financialization to take effect sometime in the 2004-2005 period. We follow these papers and begin our analysis in January 2004. Our analysis is based on approximately $3 / 4$ billion trades in commodity futures contracts observed from January 2004 through December 2013. We choose the three most heavily traded commodities in the energy, metals, grains, softs, and meats categories for a total of 15 futures contracts. Our work builds heavily on recent advances in model-free volatility and covariance measurement using high-frequency data. See for example Andersen, Bollerslev, Christoffersen \& Diebold (2013), Barndorff-Nielsen \& Shephard (2007), and Hansen \& Lunde (2011) for recent surveys.

Bakshi, Gao \& Rossi (2013) develop a three-factor commodity pricing model, using the average commodity return, a basis spread factor, and a momentum factor. They find that the model captures both the cross-sectional and time-series variation in commodity returns. Szymanowska, De Roon, Nijman \& Van Den Goorbergh (2014) also find that the basis spread factor explains the cross-section of commodity returns. Daskalaki, Kostakis \& Skiadopoulos (2014) also explore common factors in the cross-section of commodity futures returns. They test various asset pricing models motivated either by the traditional empirical equity market studies, or by available commodity pricing theories. They find that none of the models they investigate are successful and conclude 
that commodity markets are heterogeneous and segmented from the equity market. From the apparent conflict in these recent studies we conclude that the factor structure of commodity returns needs to be studied further.

The evidence on the integration of commodity and equity markets is also mixed. For early evidence on segmentation, see Bessembinder (1992), Bessembinder \& Chan (1992), and Gorton \& Rouwenhorst (2006). For recent evidence on integration, see Tang \& Xiong (2012), Henderson, Pearson \& Wang (2013), Basak \& Pavlova (2014), and Singleton (2014). We contribute to this discussion by constructing daily model-free realized market betas from high-frequency returns on commodity futures and market index futures.

Inspired by Longin \& Solnik (2001) and Ang \& Chen (2002) who study equity markets, we analyze the threshold correlations between commodity futures returns and stock market returns. We find strong evidence of tail-dependence between commodity and equity market returns suggesting important nonlinear and non-normal dependencies between commodity and equity markets.

In recent work focusing on the U.S. equity market, Chen \& Petkova (2012), Duarte, Kamara, Siegel \& Sun (2014), and Herskovic, Kelly, Lustig \& Van Nieuwerburgh (2014) find strong evidence of factor structure in idiosyncratic volatility. Herskovic et al. (2014) use daily data to compute annual firm-specific realized volatilities on a large number of stocks. They then look for and find strong commonality in the volatility of individual equities. The commonality in equity volatility is strong even after the market factor is removed. This work is important because it has the potential to explain the so-called risk anomaly documented in Ang, Hodrick, Xing \& Zhang (2006) and Ang, Hodrick, Xing \& Zhang (2009) showing that stocks with low volatility this quarter have high returns next month and vice versa. Inspired by this equity market literature, we investigate the factor structure of individual commodity volatility. We find strong evidence of a common factor in daily commodity futures volatility which we compute from intraday returns.

Our study complements Tang \& Xiong (2012) who focus on the connection between the large inflow of commodity index investments and the large increase in commodity price co-movements. They find that prices of non-energy commodity futures in the 
United States have become increasingly correlated with oil prices after 2004. Also, they find that the correlation between commodity returns and the MSCI Emerging Markets Index has been rising in recent years. Substantial increases in return correlation between commodities and stocks were also found in Büyüksahin, Haigh \& Robe (2010) using the Dynamic Conditional Correlation (DCC) model of Engle (2002). In recent work, Boons, Roon \& Szymanowska (2013) find that stocks that have high betas with a commodity index earned a relatively low average return in the pre-financialization period and a relatively high return in the post-financialization period. We investigate the dynamic relationship between commodities and the stock market using model-free realized betas. Our time-varying betas can be viewed as dynamic measures of integration with the stock market. Our work is therefore related to the research on time-varying integration of emerging markets, see, for example, Carrieri, Errunza \& Hogan (2007) and Bekaert, Harvey, Lundblad \& Siegel (2011).

The remainder of the paper is structured as follows. In Section 2 we describe the data and the methodology for computing returns and realized volatilities. Section 3 investigates the multivariate properties of commodity futures returns and volatility. Section 4 analyzes the relationship between commodities and the stock market, and Section 5 investigates the distributional properties of commodity returns and shocks. Section 6 concludes. Supplementary figures and tables are placed in the appendix.

\section{Constructing Returns and Realized Volatility}

We collect data from two main sources. High-frequency data on commodity futures are obtained from Tick Data Inc. and transaction data on the Spyder ETF are obtained from the NYSE Trade and Quote (TAQ) database. ${ }^{1}$ Spyder is used as a proxy for the stock market index. The commodity futures dataset includes intraday transactions and quotes for all traded maturities on more than 60 commodities traded across the world.

\footnotetext{
${ }^{1}$ Standard \& Poor's Depository Receipt (Spyder) is a tradable security that represents ownership in the S\&P 500 index. By using Spyder, stale price effects associated with using the S\&P 500 cash index at high frequencies are avoided.
} 


\subsection{Commodity Categories}

We study the post-financialization period from January 1, 2004 to December 31, 2013, and focus on commodities that are traded either in Chicago or New York during the entire sample period. Gorton, Hayashi \& Rouwenhorst (2012) classify commodities into five categories: metals, softs, grains, energy, and meats. We use this classification and focus on the three most actively traded commodities in each category. This leaves $K=15$ commodities for our analysis, namely light crude, natural gas, heating oil; gold, silver, copper; soybeans, corn, wheat; sugar, coffee, cotton; live cattle, lean hogs, and feeder cattle. ${ }^{2}$ See Table 1 for details on our fifteen commodities. The normalized closing prices of the commodities and Spyder are shown in Figure 1.

Table 1: The 15 Selected Commodities.

\begin{tabular}{ccccr}
\hline \hline Classification & Commodity & Exchange & Time Zone & Transactions \\
\hline Energy: & Light Crude (CL) & NYMEX/CME & New York & $217,709,630$ \\
& Natural Gas (NG) & NYMEX/CME & New York & $73,536,635$ \\
& Heating Oil (HO) & NYMEX/CME & New York & $31,931,052$ \\
Metals: & Gold (GC) & COMEX/CME & New York & $125,901,304$ \\
& Silver (SV) & COMEX/CME & New York & $43,657,064$ \\
& Copper (HG) & COMEX/CME & New York & $34,840,077$ \\
Grains: & Soybeans (SY) & CBOT/CME & Chicago & $62,056,841$ \\
& Corn (CN) & CBOT/CME & Chicago & $66,933,216$ \\
& Wheat (WC) & CBOT/CME & Chicago & $34,032,067$ \\
Softs: & Sugar \#1 (SB) & ICE & New York & $22,666,799$ \\
& Coffee “C” (KC) & ICE & New York & $10,798,589$ \\
& Cotton \#2 (CT) & ICE & New York & $8,798,184$ \\
Meats: & Live Cattle (LC) & CME & Chicago & $10,760,576$ \\
& Lean Hogs (LH) & CME & Chicago & $9,274,472$ \\
& Feeder Cattle (FC) & CME & Chicago & $1,905,263$ \\
\hline
\end{tabular}

Notes: For each commodity futures contract we report the total number of transactions available during our 2004-2013 sample period.

Not surprisingly, light crude is by far the most heavily traded commodity futures with more than 200 million transactions as seen from the last column of Table 1. Each transaction consists of at least one futures contract being traded in which 1.000 barrels of crude oil is the underlying commodity. Table 1 illustrates the massive size of the crude oil futures market compared with other commodities. Gold is second, natural gas third, corn fourth, soybeans fifth, and feeder cattle is the least traded among the fifteen

\footnotetext{
${ }^{2}$ The remaining commodities traded in Chicago or New York are palladium, ICE energy futures, lumber, cocoa, orange juice, oats, soybean meal, and soybean oil. We also do not consider platinum which only began trading in October 2007, ethanol which began trading in January 2010, rough rice that traded from January 2010, and pork bellies that traded until July 2011.
} 
commodities with less than 2 million registered transactions in our sample period. Figure 2 illustrates the development in the daily average transactions, volume, and dollar volume per year. Trading in all commodities has increased remarkably since 2006. The availability of large amounts of transactions data forms the basis of our analysis on commodity futures volatility.

\subsection{Transaction Data Cleaning}

The raw daily transactions data for the fifteen commodity futures series is cleaned using the Tick Data validation process and subsequently the algorithm in BarndorffNielsen, Hansen, Lunde \& Shephard (2009). ${ }^{3}$ We thus use the median price if multiple transactions have the same time stamp, and we delete entries for which the transaction price is more than five mean absolute deviations from a rolling centered median of the 25 preceding and the 25 subsequent observations. For the Spyder contract, entries with a transaction price equal to zero, entries with corrected trades, entries with an abnormal sale condition, and entries with prices that are above (below) the ask plus (minus) the bid-ask spread are deleted. For the univariate realized variance analysis, the widest feasible estimation window is used, and for the bivariate realized covariance analysis the window for each commodity is defined by its trading span overlap with Spyder as discussed further in Section 2.4 below. For most commodities, electronic trading is available 24 hours a day, only paused by short breaks. All this is illustrated in Figure 3, which shows the trading periods and breaks on December 30, 2013, for the 15 commodities.

\subsection{Modeling the Futures Roll and Computing Daily Returns}

For each of the fifteen commodities, a continuous price series is constructed from the nearest-to-maturity contracts in the sample period. Rollover to the subsequent

3"Algorithmic data filters are employed to identify bad prints, decimal errors, transposition errors, and other data irregularities. These filters take advantage of the fact that since we are not producing data in real-time, we have the ability to look at the tick following a suspected bad tick before we decide whether or not the tick is valid. We have developed a number of filters that identify a suspect tick and hold it until the following tick confirms its validity. The filters are proprietary, and are based upon recent tick volatility, moving standard deviation windows, and time of day." Source: www.tickdata.com. 
contract occurs on days when the daily, day-session tick volume of the back-month contract exceeds the daily tick volume of the current month contract. ${ }^{4}$ This procedure is intended to mimic the behaviour of the majority of market participants. Rollover dates are stored to allow for analysis with and without roll-returns. Roll-returns are sometimes extreme, but investors in commodity markets are exposed to them, and it is important to recognize their implications. The number of roll-returns for a commodity depends on the availability and periodicity of futures contracts and it varies in our sample period from 38 for cotton to 120 for the three energy commodities. Rollover is always done in the afternoon trading break illustrated in Figure 3.

For the univariate analysis, the first observed price for a commodity on day $t$ is taken as the opening price, $F_{t}^{o}$, and the closing price, $F_{t}^{c}$, is the last observed price before the afternoon trading break. This is indicated for Spyder in the top line in Figure 3. The commodities are treated similarly. Daily log-returns of the closing prices, $r_{t}=\ln \left(F_{t}^{c}\right)-\ln \left(F_{t-1}^{c}\right)$, are plotted in Figure A.1 in the appendix.

Table 2.a reports various descriptive statistics for the daily log returns on our 15 commodity futures. ${ }^{5}$ Consider for now the dynamic properties of commodity futures returns. The first-order autocorrelation, $\operatorname{ACF}(1)$, is significantly negative (at the $1 \%$ level) for light crude and wheat. The largest autocorrelation is $7 \%$. The Ljung-Box test that the first 5 and 21 daily autocorrelations are jointly zero are rejected for natural gas, and for light crude, copper, soybeans, and feeder cattle when using 21 lags but not when using 5 lags. Figure A. 2 in the appendix contains the autocorrelation functions for the first 60 lags which do not show any strong systematic evidence for daily return dynamics. Altogether we conclude that daily returns show little evidence of predictability based on sample autocorrelations. We therefore do not model expected return dynamics below. The distribution of commodity futures returns will be discussed in detail in Section 5.1 below.

\footnotetext{
${ }^{4}$ This can be done using "AutoRoll" in the TickWrite 7 software provided by Tick Data Inc. This way the data used in our analysis should be straightforward to reproduce.

${ }^{5}$ Table A.1.a in the appendix contains descriptive statistics for returns when roll-returns are removed.
} 


\subsection{Constructing Realized Volatilities}

Trading in the late evening hours is omitted for the purpose of computing realized volatility. The effect of this is expected to be negligible as the fraction of observations discarded by this procedure is small as indicated with the numbers in grey in Figure 3. Within the trading span, a 1-minute time-grid is constructed using previous-tick interpolation for each commodity. This results in $(n+1) 1$-minute prices where the first price in the grid is $F_{t}^{o}$. From these prices, $n 1$-minute log-returns on day $t$ are calculated as

$$
r_{t}^{(j)}=\ln \left(F_{t_{j}}\right)-\ln \left(F_{t_{j-1}}\right),
$$

where $t_{j}-t_{j-1}$ equals one minute. We can then define $(n-4) 5$-minute returns using

$$
\tilde{r}_{t}^{(k)}=\sum_{k=j}^{j+4} r_{t}^{(j)},
$$

which is a set of overlapping 5-minute returns. The 5-minute realized variance with 1-minute subsampling is then

$$
R V_{t}^{o c}=\frac{n}{n-4} \cdot \frac{1}{5} \sum_{k=1}^{n-4}\left(\tilde{r}_{t}^{(k)}\right)^{2},
$$

where the scaling factor ensures that the realized variance is unbiased. The subsampling technique uses 5-minute returns to minimize the effect of market microstructure noise on our volatility estimate and the subsampled 5-minute returns are then averaged to increase the efficiency of the estimator. This estimator is a simplified version of the estimators advocated by Zhang et al. (2005).

Finally, variance and covariance measures are matched to close-close returns following Hansen \& Lunde (2005). That is, the realized variance for the whole day based on intermittent high-frequency data is given by

$$
R V_{t}=\hat{\omega}_{1}\left(r_{t}^{c o}\right)^{2}+\hat{\omega}_{2} R V_{t}^{o c},
$$


where $\hat{\omega}_{1}$ and $\hat{\omega}_{2}$ are estimated weights as given in the notes to Table A. 2 in the appendix and $r_{t}^{c o}$ is the realized close-to-open return, i.e. $r_{t}^{c o}=\ln \left(F_{t}^{o}\right)-\ln \left(F_{t-1}^{c}\right){ }^{6}$ The $R V o l_{t}$ measure is then computed as the square root of $R V_{t}$. The time series of $R V o l_{t}$ for our 15 commodities are shown in Figure A.3 in the appendix.

\subsection{Properties of Realized Commodity Volatility}

Table 3.a reports various sample statistics for the daily realized volatilities. Table 3.a shows that $R V \mathrm{Ol}_{t}$ has high positive skewness, as well as positive excess kurtosis, which is of course not surprising. More importantly, $R V o l_{t}$ is extremely persistent. The firstorder autocorrelation is large and significant for all 15 commodities and the Ljung-Box test is highly significant for both 5 and 21 lags.

Table 3.b reports the same sample statistics as Table 3.a but now for the natural logarithm of $R V \mathrm{l}_{t}$. Note again the extremely high persistence as evidenced by the $\operatorname{ACF}(1), Q(5)$, and $Q(21)$ statistics. Figure 4 plots the autocorrelation functions for the first 60 lags for $\log \left(R V o l_{t}\right)$. The level of first-order autocorrelation varies a bit across commodities but the strong persistence is evident across our 15 commodities and we can write our first stylized fact:

Fact \#1: Daily realized commodity futures volatility has extremely high persistence.

Comparing Table 3.b with Table 3.a we also see that the $\log \left(R V o l_{t}\right)$ is much closer to normally distributed than is $R V o l_{t}$ itself; skewness is close to zero and kurtosis is close to 3 . Figure 5 reports the quantile-quantile plot of $\log \left(R V o l_{t}\right)$ which visualizes the normality of $\log \left(R V o l_{t}\right)$. The log-normal feature of $R V o l_{t}$ is well-known in other asset markets, see for example Andersen, Bollerslev, Diebold \& Labys (2001) for foreign exchange and Andersen, Bollerslev, Diebold \& Ebens (2001) for equities. To our knowledge, we are the first to document that:

Fact \#2: The logarithm of realized commodity futures volatility is close to normally distributed.

\footnotetext{
${ }^{6}$ Table A.2 is similar to Table 2 in Hansen \& Lunde (2005), and shows the estimated values used in the computation of the realized variances for the individual commodities. The $1 \%$ largest squared overnight returns and the $0.5 \%$ largest realized covariances were omitted from the estimation.
} 
Given the approximately normal distribution of log-realized volatility found in Table 3.b, we model the expected $\log \left(R V o l_{t}\right)$ and use an $\operatorname{ARMA}(1,1)$ specification, defined by

$$
\log \left(R V o l_{t}\right)=\phi_{0}+\phi_{1} \log \left(R V o l_{t-1}\right)+\theta_{1} e_{t-1}+e_{t}
$$

We choose an ARMA $(1,1)$ specification to capture the strong persistence in log $\left(R V o l_{t}\right)$ and also to capture the unavoidable measurement error in the realized variance measure defined in equation 1 above. ${ }^{7}$ Table A.3.a in the appendix contains the ARMA-coefficient estimates. Figure 6 contains time series plots of the expected one-day ahead $\log \left(R V o l_{t}\right)$ computed as

$$
E_{t-1}\left[\log \left(R V o l_{t}\right)\right]=\phi_{0}+\phi_{1} \log \left(R V o l_{t-1}\right)+\theta_{1} e_{t-1}
$$

For comparison, we also plot the realized stock market volatility (in grey) using the Spyder futures contract. ${ }^{8}$ Note that the commodity $\log \left(R V o l_{t}\right)$ - unlike the $R V o l_{t}$ levels - are fairly well-behaved over time and in some cases shows a slightly decreasing trend over time. The concern of increased commodity market volatility often raised in the popular press does therefore not appear to be warranted.

\section{Factor Structure in Commodity Returns and Volatility}

In this section we investigate the multivariate properties of commodity returns and volatility. We pay particular attention to the factor structure in the cross-section of commodities.

\subsection{A Common Factor in Commodity Returns?}

In order to get a quick first glance at the cross-commodity return dependence, the upper triangle of the matrix in Table 4 reports the sample correlations for daily futures returns. Note the high correlations for energy and metals, the somewhat lower correlations for

\footnotetext{
${ }^{7}$ Using a fractionally integrated ARFIMA $(1, d, 1)$ model to capture the long memory in volatility does not change any of our conclusions nor does recursively estimating the ARMA $(1,1)$ model.

${ }^{8}$ Figure A.4 in the appendix contains time series plots of the raw $\log \left(R V o l_{t}\right)$ series.
} 
grains and softs, and the close-to-zero correlations for meats. The average correlation with all other commodities is highest for light crude at $34 \%$ and lowest for lean hogs at $12 \%$. The diversification benefits thus varies greatly across commodities. The average correlation across all pairs of commodity returns is $25 \%$.

We now investigate the evidence of a common factor in our 15 commodity returns. Using the sample correlations in the upper triangle of Table 4, we compute the principal components (PCs) for the 15 return series and in Figure 7.a we plot the cumulative return for the first four PCs. The first four PCs explain 30\%, 15\%, 10\%, and 7\% respectively, for a total of $62 \%$ of the cross-sectional variation in the 15 commodity futures returns. Comparing the top-left panel in Figure 7.a with the top-left panel in Figure 1 we see that the first PC appears to capture the 2007-08 run up, and subsequent crash in oil prices.

Table 5.a reports the regressions of each commodity on the first four PCs. For each commodity we run a separate PC analysis based only on the other 14 commodities to avoid endogeneity issues in these regressions. See from the $R^{2}$ how all 15 commodities load positively on the first PC. Note also that the first four factors explain much of the variation in oil, metals and grains, much less so for softs, and virtually none for meats. The average $R^{2}$ across the 15 commodity return regressions is $23 \%$. We conclude:

Fact \#3: There is some evidence of a factor structure in daily commodity futures returns excluding meats.

\subsection{A Common Factor in Commodity Volatility?}

Our daily realized volatility measures computed from intraday returns allow us to view volatility as an observed time series albeit measured with error. We therefore now investigate the multivariate properties of our 15 commodity $\log \left(R V_{t}\right)$. The bottom triangle of the matrix in Table 4 contains the sample correlations for $\log \left(R V o l_{t}\right)$. Note that the correlations for log volatility is higher than for returns for all of the 15 commodities. This is particularly the case for meats, where the average return correlation for live cattle, lean hogs, and feeder cattle is $20 \%, 12 \%$, and $14 \%$ respectively, whereas their average $\log \left(\mathrm{RVol}_{t}\right)$ correlations are $52 \%, 48 \%$, and $49 \%$. The average correlation across all pairs of commodity volatilities is $46 \%$ compared with $25 \%$ for returns. 
The first four principal components corresponding to the ARMA $(1,1)$ filtered $\log \left(R V o l_{t}\right)$ are reported in Figure 7.b. The first four PCs capture 50\%,11\%,10\%, and 6\% respectively, for a total of $77 \%$ of the total variation. Note again that the first PC for expected $\log \left(R V o l_{t}\right)$ in the top left panel of Figure 7.b resembles quite closely the time series of expected $\log \left(R V o l_{t}\right)$ for light crude in the top left panel of Figure 6.

Table 5.b reports the regressions of each expected $\log \left(R V o l_{t}\right)$ on the first four PCs. For each commodity, we again run a separate PC analysis based only on the other 14 commodities to avoid endogeneity issues in these regressions. Note that all 15 commodities load positively on the first factor. Table 5.b also reports the regression fit, $R^{2}$, of each commodity. They show that the first four PCs capture a substantial share of the variation for all commodities except perhaps coffee. The average $R^{2}$ is $54 \%$ for volatility compared with $23 \%$ for returns. Compared with the commonality in returns, the commonality in volatility is much greater. We conclude:

Fact \#4: The factor structure in daily commodity futures volatility is much stronger than the factor structure in returns.

\subsection{Time-Varying Commodity Market Integration}

It is natural to ask if the principal component analysis in Table 6 is stable over time. In a study of international equity markets by Pukthuanthong \& Roll (2009), they introduce a measure of time-varying market integration which is based on a time-varying principal component analysis. Following their approach we regress the return for each commodity on the first 10 PCs computed separately for each year and computed using only the other 14 commodities. ${ }^{9}$ Using only daily returns within a given calendar year, the measure of time-varying market integration of Pukthuanthong \& Roll (2009) consists of the time series of the annual adjusted $R^{2}$ from these return regressions. While Pukthuanthong \& Roll (2009) only carry out the integration analysis on returns, we conduct their analysis first for returns and then for expected log-realized volatility.

Our results are reported in Figure 8. The adjusted $R^{2}$ from the return regressions are shown with a black line and the adjusted $R^{2}$ from the volatility regressions are shown

\footnotetext{
${ }^{9}$ Our results are robust when changing the number of PCs used.
} 
in grey. Three important conclusions are obtained from Figure 8. First, the evidence for commodity market integration is generally stronger when based on volatility than when based on returns. This is especially true for livestock. Second, the degree of market integration varies greatly by commodity. It is strongest for oil and metals. Third, there is no obvious evidence of a time-trend in the degree of market integration during our 2004-2013 sample period. Indeed, the Pukthuanthong \& Roll (2009) market integration measure for returns decreased in 2013 for all commodities except gold and silver. Note further that for several commodities the market appears to be less integrated in 2013 than in 2004 by this measure. We conclude:

Fact \#5: There is little evidence of a time-trend in the degree of integration across commodity futures markets during the 2004-2013 period.

\section{The Stock Market as Factor for Commodity Returns and Volatility}

In this section we study the extent to which daily commodity returns and volatilities are integrated with equity market returns and volatilities. We use intraday trades on the Spyder futures contract to compute realized stock market volatility as described in Section 2 above. We then assess the ability of Spyder returns and realized volatility to explain commodity futures and returns in comparison with the four principal components used above. Finally, we construct realized covariance measures which enable us to construct realized betas and realized systematic risk ratios.

\subsection{Spyder as an Observed Factor for Commodity Returns and Volatility}

The second to last line in Table 4 shows the sample correlation between Spyder returns and the return of each commodity. The correlations range from $6 \%$ for lean hogs to $45 \%$ for copper. The average correlation with Spyder returns is $22 \%$. The last line in Table 4 shows the correlation between Spyder volatility and the volatility of each commodity. The correlations are generally high with an average of $37 \%$. They are highest for light crude and the three metals. It is lowest for coffee and natural gas which are outliers 
in this regard. The Spyder volatilities are plotted in grey along with each commodity volatility in Figure 6.

In Table 5.a we assessed the ability of the first four principal components for the commodities to explain the variation in returns and volatility over time. The principal components can be viewed as unobserved factors and the obvious next step is to ask if any observed factors can capture the variation in the PCs and thus in the commodity returns and volatility? We now want to assess the ability of Spyder to serve as an observed factor for the commodity futures market.

To this end we first regress each commodity PC on Spyder to obtain a Spyderorthogonalized PC series from the residuals. We then regress the return for each commodity on the Spyder return as well as on the four orthogonalized principal components. Again, the PCs used for each commodity are constructed from the remaining 14 commodities only.

Table 6.a contains the results for returns. The results show that the Spyder return is significant in all 15 commodity return regressions. The coefficient ranges from around $15 \%$ for livestock and gold to around more than $50 \%$ for the other metals and oil. The average regression $R^{2}$ is $24 \%$.

In Table $6 . \mathrm{b}$ we report on regressions for expected realized volatility. Again, we first orthogonalize each of the PC expected volatility factors with expected Spyder volatility. Table 6.b shows that the Spyder coefficients are significant in 13 out of 15 cases. The exceptions are natural gas and coffee. The average $R^{2}$ is $55 \%$.

Consider finally the sample correlation between Spyder volatility and the first four commodity volatility PCs plotted in Figure 7.b. The four correlations are $65 \%, 32 \%,-2 \%$, and $-20 \%$ respectively (not reported in the tables). This shows that the most important factor for commodity volatility is very highly correlated with stock market volatility, and we can write:

Fact \#6: The strong common factor in commodity volatility is largely driven by stock market volatility. 


\subsection{Constructing Realized Covariance Measures}

Our next task is to compute daily realized covariance measures for each commodity with Spyder. The ultimate goal is to compute stock market betas for each commodity that vary daily without imposing a particular dynamic model a priori.

For the bivariate analysis with Spyder, overlapping trading spans between commodity $i$ and Spyder is required to avoid a bias towards zero in the realized covariances. Therefore, opening and closing prices are now redefined as the most recently observed price before the start and end of the overlapping trading span between commodity $i$ and Spyder, respectively. This is illustrated by the grey shading in Figure 3. Spyder trades on NASDAQ from 9.30 to 16.00 in the full sample period, but for commodities the futures trading spans have changed several times. Therefore, the overlapping trade spans varies across commodities and over time. See Table A.4 in the appendix for details.

The construction of realized covariances is similar to the construction of the realized variances above. Within overlapping trade spans, a synchronised 1-minute time-grid between the commodities and Spyder is constructed. From the synchronised prices, 1-minute log-returns on day $t$ are calculated. Then, using overlapping 5-minute returns as in Section 2.4, the realized covariance with 1-minute subsampling is for commodity $i$ calculated as,

$$
R \operatorname{Cov}_{i, t}^{o c}=\frac{n(i)}{n(i)-4} \cdot \frac{1}{5} \sum_{k=1}^{n(i)-4} \tilde{r}_{i, t}^{(k)} \tilde{r}_{S P Y, t^{\prime}}^{(k)}
$$

where we again use a rescaling to make sure the realized covariance estimate is unbiased. The subsampling technique is used to eliminate bias from market microstructure noise and non-synchronous trades within the overlapping trading span, see e.g. BarndorffNielsen \& Shephard (2004).

Finally, realized variance and covariance measures are matched to close-close returns following Hansen \& Lunde (2005). That is, the realized covariance matrix for the whole day based on intermittent high-frequency data is for commodity $i$ and Spyder given by

$$
R \operatorname{Cov}_{i, t}=\hat{\omega}_{1} r_{i, t}^{c o} t_{S P Y, t}^{c o}+\hat{\omega}_{2} R \operatorname{Cov}_{i, t}^{o c}
$$


where $r_{i, t}^{c o}$ and $r_{S P Y, t}^{c o}$ is the realized close-to-open return, e.g. $r_{i, t}^{c o}=\ln \left(F_{i, t}^{o}\right)-\ln \left(F_{i, t-1}^{c}\right)$, for commodity $i$ and Spyder respectively, and $\hat{\omega}_{1}$ and $\hat{\omega}_{2}$ are again estimated weights similar to the ones reported for the univariate case in Table A.2 in the appendix.

\subsection{Realized Spyder Betas for Commodities}

We now investigate the ability of the stock market to explain the variation in returns on the 15 commodity futures contracts. Recognizing that the relationship between each commodity and the stock market is likely changing over time, we follow Andersen, Bollerslev, Diebold \& Wu (2005) and Patton \& Verardo (2012) who use intraday data to compute a daily model-free realized beta for each asset defined by

$$
R \beta_{i, t}=\frac{R \operatorname{Cov}_{i, t}}{R V_{S P Y, t}}
$$

The realized covariance, $R \operatorname{Cov}_{i, t}$, is calculated on the cross-product of the intraday commodity and stock market return using the estimator in equation 3.

In order to filter the realized betas in equation 4 we estimate an $\operatorname{ARMA}(1,1)$ on each realized beta series. The time series of the filtered betas are plotted in Figure 9 and the ARMA coefficients are reported in Table A.3.b in the appendix. The appendix also contains a plot of the raw realized betas in Figure A.5.

We plot the beta series along with bootstrapped $75 \%$ and $90 \%$ confidence intervals constructed by resampling with replacement from the ARMA residuals. The confidence intervals are based on 10,000 bootstrap samples.

Figure 9 shows that the realized betas were close to zero until 2008, then rose dramatically in many cases to and even beyond one. The decrease in commodity betas since 2010 are equally interesting. By the end of 2013 all the realized betas were back to zero, the level at which they began at the onset of financialization in 2004 . The betas were highest for energy and metals. The remarkable rise and fall of the commodity betas are shared by all except for lean hogs and feeder cattle which stayed close to zero throughout the period. We assert:

Fact \#7: Commodity betas with the stock market were high during 2008-2010 but have since returned to a level close to zero. 
The beta of an asset does not tell us how much of the variance in the asset's return is driven by the market factor. To this end we define the Systematic Risk Ratio (SRR) for commodity $i$ by

$$
S S R_{i, t}=\frac{R \beta_{i, t}^{2} \cdot R V_{S P Y, t}}{R V_{i, t}}
$$

The SSR can thus be interpreted as the fraction of commodity $i$ variance that is explained by market variance. Clearly, $0 \leq S S R_{i, t} \leq 1$. Our use of high-frequency data enables us to compute a systematic risk ratio for each commodity on each day. We again estimate an ARMA $(1,1)$ on the raw SRR to filter the series. The ARMA coefficients and the raw SRR series are provided in the appendix. Figure 10 plots the time series of the filtered SRR along with the average SRR over the sample period with bootstrapped $75 \%$ and 90\% confidence intervals for the ARMA residuals. Note how the SRR was close to zero for all commodities before 2008, it then rose to substantial levels - in particular for energy and metals - before returning to zero at the end of 2013.

\subsection{Capturing Nonlinear Dependence with Spyder}

So far we have focused on linear dependence between commodity futures and the stock market. In this section we investigate nonlinear relationships.

Figure 11 shows the threshold correlations for each daily commodity futures returns versus the daily return on the stock index ETF. Threshold correlations are computed as

$$
\rho_{i j}(u)= \begin{cases}\operatorname{Corr}\left(r_{i}, r_{j} \mid r_{i}<F_{i}^{-1}(u) \text { and } r_{j}<F_{j}^{-1}(u)\right) & \text { if } u<0.5 \\ \operatorname{Corr}\left(r_{i}, r_{j} \mid r_{i} \geq F_{i}^{-1}(u) \text { and } r_{j} \geq F_{j}^{-1}(u)\right) & \text { if } u \geq 0.5,\end{cases}
$$

where $u$ is a threshold between 0 and 1 , and $F_{i}^{-1}(u)$ is the empirical quantile of the univariate distribution of $r_{i}$. The horizontal axis in Figure 11 denotes the percentile used to define each threshold for the correlation on the vertical axis. We only compute the threshold correlation when at least 60 observations are available, and again we perform the calculations with (black lines) and without (grey lines) rollover returns.

The dashed lines in Figure 11 denotes the threshold correlation from a bivariate 
normal distribution with a correlation equal to the sample correlation from the futures data. Figure 11 shows that the deviation from bivariate normality is large for oil, all metals, and for some of the agriculturals as well. While the simple linear correlations can be small, the threshold correlations are often large. It is important to keep in mind that the threshold correlations are unconditional - they are computed once from the entire sample. Figure 9 above showed that the stock market exposure of each commodity varies greatly over time. This dynamic beta may be the cause of the large threshold correlations we see in Figure 11.

We next compute threshold correlations for the expected $\log \left(R V o l_{t}\right)$ for each commodity versus $\log \left(R V o l_{t}\right)$ in Spyder. They are plotted in Figure 12 which shows that large positive shocks to volatility in the stock market are generally highly correlated with large positive shocks to the volatility of each commodity. This is particularly true for oil and metals but also for most of the agriculturals.

\section{The Distribution of Commodity Returns and Shocks}

So far, we have focused on the dependence structure across commodity futures returns and volatilities. To obtain a fully specified model, we need to make distributional assumptions as well. We therefore now investigate the distribution of futures returns and the extent to which standardizing the daily commodity futures returns by expected realized volatility will produce a close to normally distributed series of commodity futures shocks.

\subsection{The Distribution of Commodity Futures Returns}

As mentioned above, Table 2.a reports various sample statistics for the daily log returns on our 15 commodity futures. During our 2004-2013 sample period, the average log return was highest for silver at 4.7 bps per day and lowest for natural gas at $-1.5 \mathrm{bps}$ per day. Heating oil, copper, gold, and light crude appreciated strongly during the sample as well. Natural gas had by far the highest average daily volatility at more than $3.3 \%$ per day compared with feeder cattle which only had a volatility of less than $1 \%$ 
per day. These findings also hold when the rollover returns are removed. We note that the cross-commodity variation in commodity return mean and volatility is large.

Table 2.a also provides information on the unconditional distribution of daily returns. Cotton contains by far the largest negative daily return at $-39.3 \%$, which is a 19 standard deviation move that occurred on February 16, 2011. This corresponds to a rollover return. Lean hogs has the largest positive daily return at $25.9 \%$ which also corresponds to a rollover return. However, even with rollovers removed, the minimum and maximum observations for all commodities are quite extreme; perhaps with the exception of live and feeder cattle. Not surprisingly, given the extreme minimum value, cotton has the largest negative skewness at -2.5 . Lean hogs has the highest positive skewness at 2.0. The cross-sectional range in skewness is thus large. Kurtosis is in excess of the Gaussian value of 3 for all 15 commodities. It is not surprisingly largest at 54.2 for cotton whereas coffee has the lowest value at 3.9. Results are very different for both skewness and kurtosis for most commodities when rollover returns are removed. In this case, silver is the commodity with both the largest (negative) skewness and kurtosis. These findings are not surprising because sample estimates of skewness and kurtosis are well-known to be heavily influenced by a few large outlying observations, see Kim \& White (2004).

Figure A.6 in the appendix reports QQ plots against the normal distribution which provides further evidence on the non-normality of raw returns and the important impact on the tail of the distribution from roll-returns. For now, we simply note that the unconditional distribution of commodity returns is highly leptokurtotic with substantial variation in skewness across commodities.

\subsection{Commodity Futures Shocks}

If we assume that $e_{t}$ is i.i.d. normally distributed, which is sensible given Table 3.b, then we can use the moment-generating function of a normal variable to construct our measure of expected $R V \mathrm{l}_{t}$, as

$$
E_{t-1}\left[R V o l_{t}\right]=\exp \left[E_{t-1}\left[\log \left(R V o l_{t}\right)\right]\right] \cdot \exp \left[\frac{1}{2} \sigma_{e}^{2}\right]
$$


where $\sigma_{e}^{2}=\operatorname{Var}\left[e_{t}\right]$. We can now compute the time series of unexpected commodity futures shocks, $z_{t}$, via

$$
z_{t}=\frac{r_{t}-\frac{1}{T} \sum_{i=1}^{T} r_{i}}{E_{t-1}\left[R V o l_{t}\right]}
$$

Note that we deliberately standardize returns by the ex-ante expected volatility and not by the ex-post realized volatility as is sometimes done in the literature. We are interested in the conditional distribution of one-day-ahead returns, that is, the distribution of $z_{t}$. We use the full-sample average as an estimate of the mean return, but using a recursive or rolling sample average has no impact on the conclusions below.

Table 2.b reports the sample statistics for $z_{t}$ for each of our 15 commodities. As expected, the mean of the shock is approximately zero and the standard deviation is close to one for each commodity. More importantly, note that the non-normality strongly evident in Table 2.a is much less apparent in Table 2.b. Figure 13 shows the quantile-quantile plots of $z_{t}$. There is a drastic difference between the quantile-quantile plots of returns in Figure A.6 and the quantile-quantile plots of shocks in Figure 13, even though the data quantiles on the vertical axis still exhibits fatter tails than the standard normal quantiles on the horizontal axis particularly for the agricultural commodities. We conclude that:

Fact \#8: Commodity futures returns standardized by expected realized volatility are closer to normally distributed than the returns themselves but still display leptokurtosis.

Finding a parametric distribution that fits the return shocks in Figure 13 is important in option valuation and risk management applications but not for our analysis and we therefore leave this task for future work. The normal-lognormal mixture model suggested in Andersen, Bollerslev, Diebold \& Labys (2003) or the $t$-distribution used in Maheu \& McCurdy (2011) should be viable approaches in this regard.

Note also that we have assumed that the volatlity of volatility, $\sigma_{e}^{2}$, is constant. Dynamics could be modelled using the approach in Maheu \& McCurdy (2011) but they find that it makes little difference for the purpose of density forecasting and so we simply let $\sigma_{e}^{2}$ be constant. We instead turn our attention to our main task which is 
uncovering the stylized fact of the joint distribution of commodity futures returns as well as of their volatilities.

Figure A.7 in the appendix shows the threshold correlations for the return shocks, $z_{t}$. Note that they are very close to zero for all commodities except coffee. Coffee is clearly affected by rollover returns, but is also the only commodity with periodicity in volatility as it is evident from Figure 5. Comparing Figure 11 with Figure A.7 suggests that the large threshold correlations in returns are driven by time-varying volatility, so that when dynamically standardized, commodity returns show little evidence of significant threshold correlations.

\section{Conclusion}

We have addressed the following questions:

First, what are the stylized facts of commodity futures returns and volatility post financialization? Second, is there a factor structure in commodity futures returns? Third, is the stock market driving the common component of commodity futures returns? Fourth, do the stock market betas of commodity futures returns vary significantly over time? Fifth, does the ratio of commodity futures return volatility explained by the stock market beta change over time? Sixth, is there a factor structure in commodity futures volatility? Finally, is stock market volatility driving the common component of commodity futures volatility?

Analyzing almost a billion trades on 15 commodity futures contracts for the 20042013 period, we have uncovered the following:

Fact \#1: Daily realized commodity futures volatility has extremely high persistence.

Fact \#2: The logarithm of realized commodity futures volatility is close to normally distributed.

Fact \#3: There is some evidence of a factor structure in daily commodity futures returns excluding meats.

Fact \#4: The factor structure in daily commodity futures volatility is much stronger than the factor structure in returns. 
Fact \#5: There is little evidence of a time-trend in the degree of integration across commodity futures markets during the 2004-2013 period.

Fact \#6: The strong common factor in commodity volatility is largely driven by stock market volatility.

Fact \#7: Commodity betas with the stock market were high during 2008-2010 but have since returned to a level close to zero.

Fact \#8: Commodity futures returns standardized by expected realized volatility are closer to normally distributed than the returns themselves but still display leptokurtosis.

An appropriate option valuation model or portfolio risk model for commodity futures needs to incorporate these features. We have deliberately taken a model-free approach in this paper. But our results suggest that the parametric models developed in Andersen et al. (2003) and Maheu \& McCurdy (2011) present viable approaches.

Our results also show that the fear of increased volatility in the commodity markets as a consequence of financialization is largely overblown. Commodity volatility has not trended up nor has commodity return covariance with the stock market trended up. Commodity returns are not riskier now than a decade ago and commodities do not appear to have lost their ability to diversify equity market exposure.

Finally, our results have important implications for understanding the cross-section of commodity futures returns. In recent work focusing on the U.S. equity market, Chen \& Petkova (2012), Duarte, Kamara, Siegel \& Sun (2014), and Herskovic, Kelly, Lustig \& Van Nieuwerburgh (2014) find very strong evidence of factor structure in idiosyncratic volatility. We find the same to be true in commodity futures volatility. Developing an asset pricing framework that can capture this feature presents an important challenge for future work. 


\section{References}

Andersen, T., Bollerslev, T., Christoffersen, P. \& Diebold, F. (2013), Financial risk measurement for financial risk management, in G. Constantinides, M. Harris \& R. Stulz, eds, 'Handbook of the Economics of Finance', Vol. 2B, Elsevier, pp. 1127-1220.

Andersen, T. G., Bollerslev, T., Diebold, F. X. \& Ebens, H. (2001), 'The distribution of realized stock return volatility', Journal of Financial Economics 61(1), 43-76.

Andersen, T. G., Bollerslev, T., Diebold, F. X. \& Labys, P. (2001), 'The distribution of exchange rate volatility', Journal of the American Statistical Association 96(453), 42-55. Correction published in 2003, volume 98, page 501.

Andersen, T. G., Bollerslev, T., Diebold, F. X. \& Labys, P. (2003), 'Modeling and forecasting realized volatility', Econometrica 71(2), 579-625.

Andersen, T. G., Bollerslev, T., Diebold, F. X. \& Wu, J. (2005), 'A framework for exploring the macroeconomic determinants of systematic risk', American Economic Review 95(2), 398-404.

Ang, A. \& Chen, J. (2002), 'Asymmetric correlations of equity portfolios', Journal of Financial Economics 63(3), 443-494.

Ang, A., Hodrick, R. J., Xing, Y. \& Zhang, X. (2006), 'The cross-section of volatility and expected returns', Journal of Finance 61(1), 259-299.

Ang, A., Hodrick, R. J., Xing, Y. \& Zhang, X. (2009), 'High idiosyncratic volatility and low returns: International and further U.S. evidence', Journal of Financial Economics 91(1), 1-23.

Baker, S. D. (2014), The financialization of storable commodities, Working paper, University of Virginia.

Baker, S. D. \& Routledge, B. (2012), The price of oil risk, Working paper, Carnegie Mellon University. 
Bakshi, G., Gao, X. \& Rossi, A. (2013), Asset pricing models that explain the cross-section and time-series of commodity returns, Working paper, University of Maryland.

Barndorff-Nielsen, O. E., Hansen, P. R., Lunde, A. \& Shephard, N. (2009), 'Realised kernels in practice: Trades and quotes', Econometrics Journal 12, C1-C32.

Barndorff-Nielsen, O. E. \& Shephard, N. (2004), 'Econometric analysis of realised covariation: High frequency based covariance, regression and correlation in financial economics', Econometrica 72, 885-925.

Barndorff-Nielsen, O. E. \& Shephard, N. (2007), Variation, jumps and high frequency data in financial econometrics, in R. Blundell, T. Persson \& W. K. Newey, eds, 'Advances in Economics and Econometrics. Theory and Applications, Ninth World Congress', Econometric Society Monographs, Cambridge University Press, pp. 328372.

Basak, S. \& Pavlova, A. (2014), A model of financialization of commodities, Working paper, London Business School.

Bekaert, G., Harvey, C. R., Lundblad, C. T. \& Siegel, S. (2011), 'What Segments Equity Markets?', Review of Financial Studies 24(12), 3841-3890.

Bessembinder, H. (1992), 'Systematic risk, hedging pressure, and risk premiums in futures markets', Review of Financial Studies 5(4), 637-67.

Bessembinder, H. \& Chan, K. (1992), 'Time-varying risk premia and forecastable returns in futures markets', Journal of Financial Economics 32(2), 169-193.

Boons, M., Roon, F. \& Szymanowska, M. (2013), 'The stock market price of commodity risk', Working paper, Tilburg University .

Büyüksahin, B., Haigh, M. S. \& Robe, M. A. (2010), 'Commodities and equities: A "market of one"?', Journal of Alternative Investments $\mathbf{1 2 .}$

Carrieri, F., Errunza, V. \& Hogan, K. (2007), ‘Characterizing world market integration through time', Journal of Financial and Quantitative Analysis 42, 915-940. 
Chen, Z. \& Petkova, R. (2012), 'Does idiosyncratic volatility proxy for risk exposure?', Review of Financial Studies 25(9), 2745-2787.

Cheng, I.-H. \& Xiong, W. (2013), The financialization of commodity markets, NBER working papers, National Bureau of Economic Research, Inc.

Daskalaki, C., Kostakis, A. \& Skiadopoulos, G. (2014), 'Are there common factors in individual commodity futures returns?', Journal of Banking E Finance 40(C), 346-363.

Duarte, J., Kamara, A., Siegel, S. \& Sun, C. (2014), 'The systematic risk of idiosyncratic volatility', SSRN Working Paper.

Engle, R. F. (2002), ‘Dynamic conditional correlation - a simple class of multivariate GARCH models,', Journal of Business E Economic Statistics 20(3), 339-350.

Gorton, G. B., Hayashi, F. \& Rouwenhorst, G. K. (2012), 'The fundamentals of commodity futures returns', Yale ICF Working paper No. 07-08.

Gorton, G. \& Rouwenhorst, K. G. (2006), 'Facts and fantasies about commodity futures', Financial Analysts Journal pp. 47-68.

Hamilton, J. D. \& Wu, J. C. (2014), Effects of index-fund investing on commodity futures prices, NBER working paper, National Bureau of Economic Research, Inc.

Hansen, P. R. \& Lunde, A. (2005), 'A realized variance for the whole day based on intermittent high-frequency data', Journal of Financial Econometrics 3, 525-544.

Hansen, P. R. \& Lunde, A. (2011), Forecasting volatility using high-frequency data, in M. Clements \& D. Hendry, eds, 'The Oxford Handbook of Economic Forecasting', Oxford: Blackwell, chapter 19, pp. 525-556.

Henderson, B., Pearson, N. \& Wang, L. (2013), New evidence on the financialization of commodity markets, Working paper, University of Illinois at Urbana-Champaign.

Herskovic, B., Kelly, B., Lustig, H. \& Van Nieuwerburgh, S. (2014), The common factor in idiosyncratic volatility: Quantitative asset pricing implications, Working paper, University of Chicago, Booth School of Business. 
Kim, T.-H. \& White, H. (2004), 'On more robust estimation of skewness and kurtosis', Finance Research Letters 1(1), 56-73.

Longin, F. \& Solnik, B. (2001), 'Extreme correlation of international equity markets', The Journal of Finance 56(2), 649-676.

Maheu, J. M. \& McCurdy, T. H. (2011), ‘Do high-frequency measures of volatility improve forecasts of return distributions?', Journal of Econometrics 160(1), 69-76.

Patton, A. J. \& Verardo, M. (2012), 'Does beta move with news? firm-specific information flows and learning about profitability', Review of Financial Studies 25(9), 2789-2839.

Pukthuanthong, K. \& Roll, R. (2009), 'Global market integration: An alternative measure and its application', Journal of Financial Economics 94(2), 214-232.

Singleton, K. J. (2014), 'Investor flows and the 2008 boom/bust in oil prices', Management Science 60(2), 300-318.

Szymanowska, M., De Roon, F., Nijman, T. \& Van Den Goorbergh, R. (2014), 'An anatomy of commodity futures risk premia', The Journal of Finance 69(1), 453-482.

Tang, K. \& Xiong, W. (2012), 'Index investment and financialization of commodities', Financial Analysts Journal 68, 54-74.

Zhang, L., Mykland, P. A. \& Aït-Sahalia, Y. (2005), 'A tale of two time scales: Determining integrated volatility with noisy high frequency data', Journal of the American Statistical Association 100, 1394-1411. 
Figure 1: Daily Closing Prices for 15 Commodities and Spyder. Normalized.
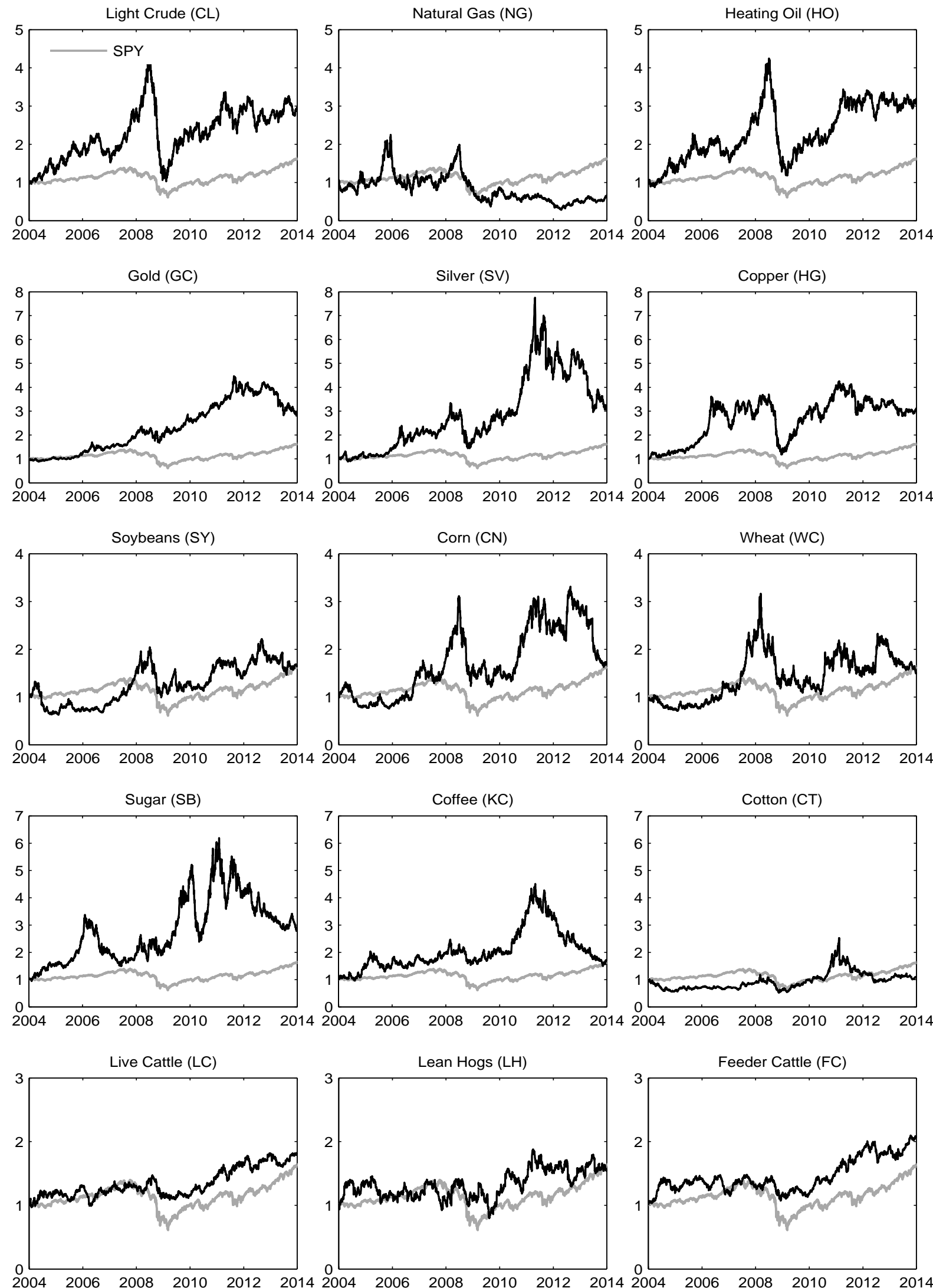
Figure 2: Number of Ticks, Volume and Dollar Volume for 15 Commodities. Annual Averages.
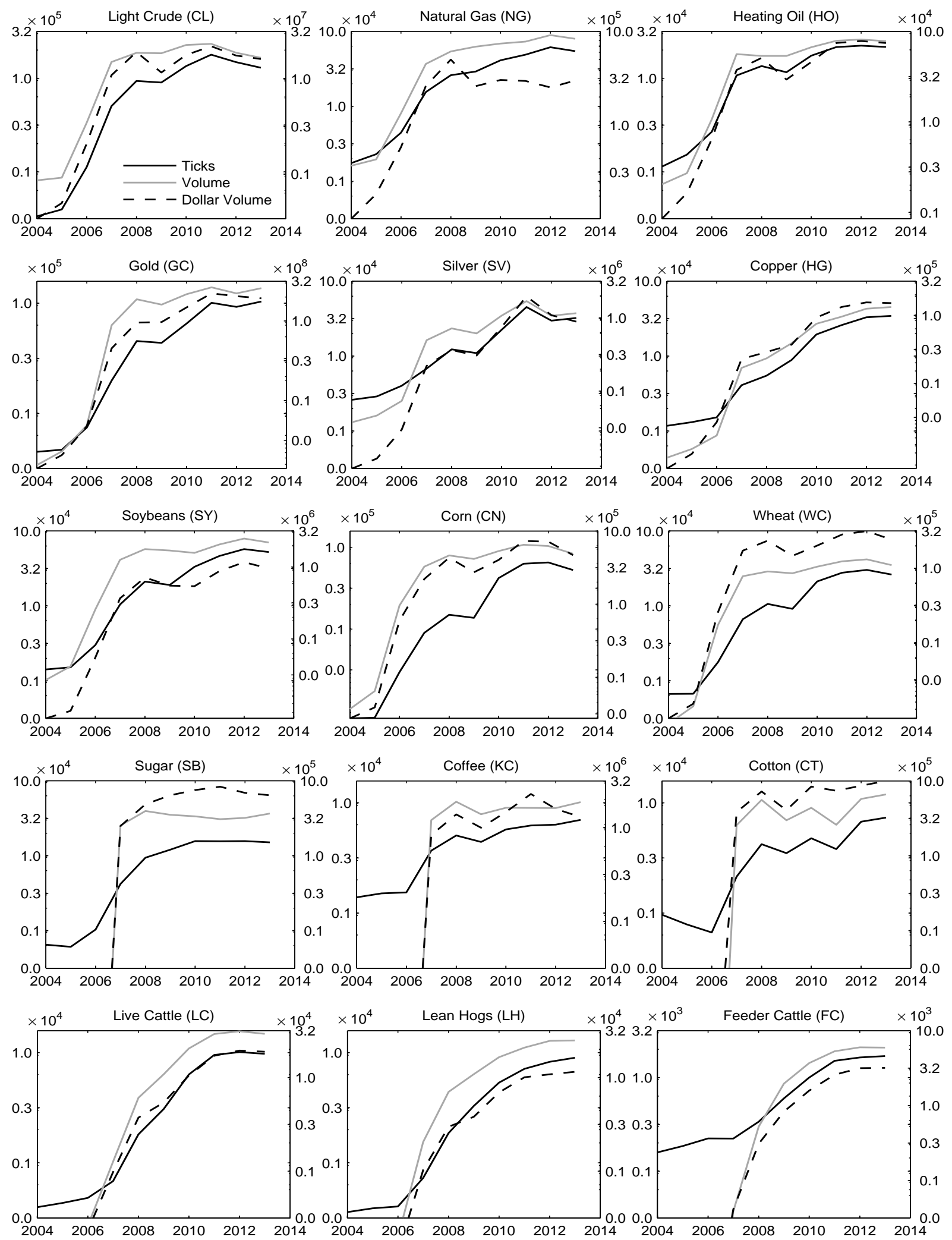

Notes: Ticks (left axis) denote the number of transactions, which may consist of one or more futures contracts (pit and electronic). Volume (left axis) denotes the number of futures contracts traded (electronic only), Dollar Volume (right axis) denotes the dollar value of the futures contracts traded using the closing price each day (electronic only). 
Figure 3: Daily Trading Hours for 15 Commodities and Spyder.

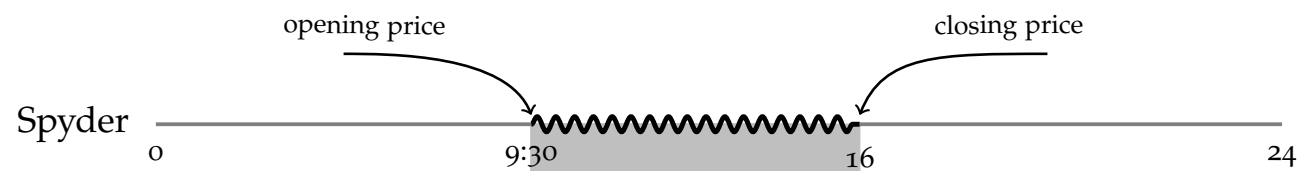

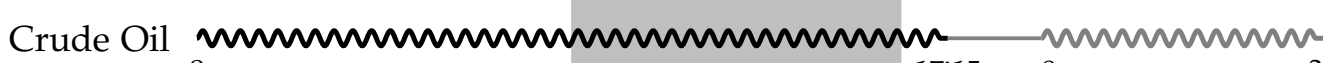
$\begin{array}{lllll}0 & 17: 15 & 18 & 5.3 \% & 24\end{array}$

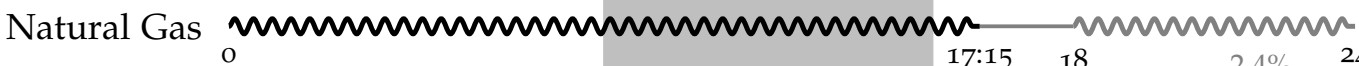

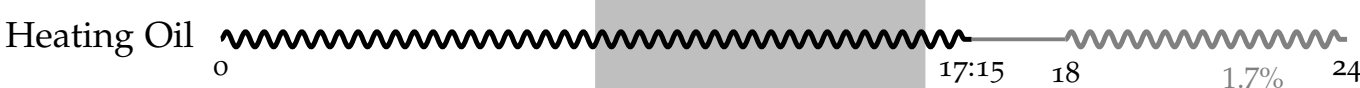

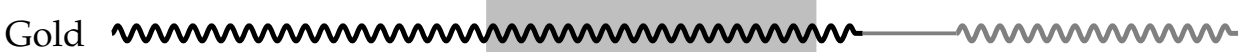
$\begin{array}{lllll}17: 15 & 18 & 7.7 \% & 24\end{array}$ Silver

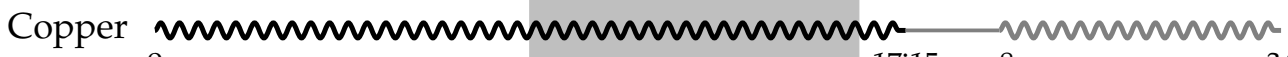
\begin{tabular}{lllll}
\hline & 18 & &
\end{tabular}

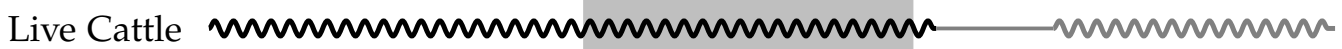

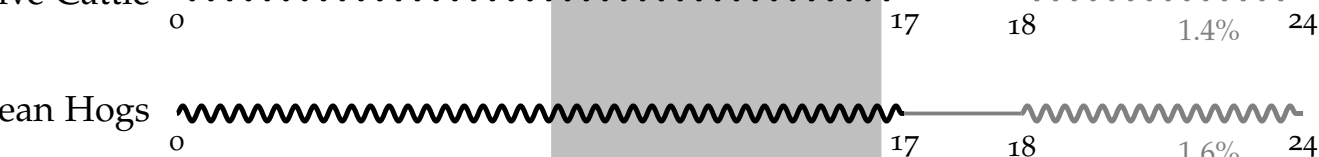

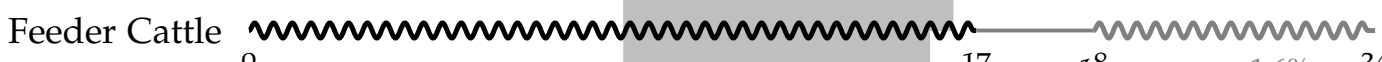
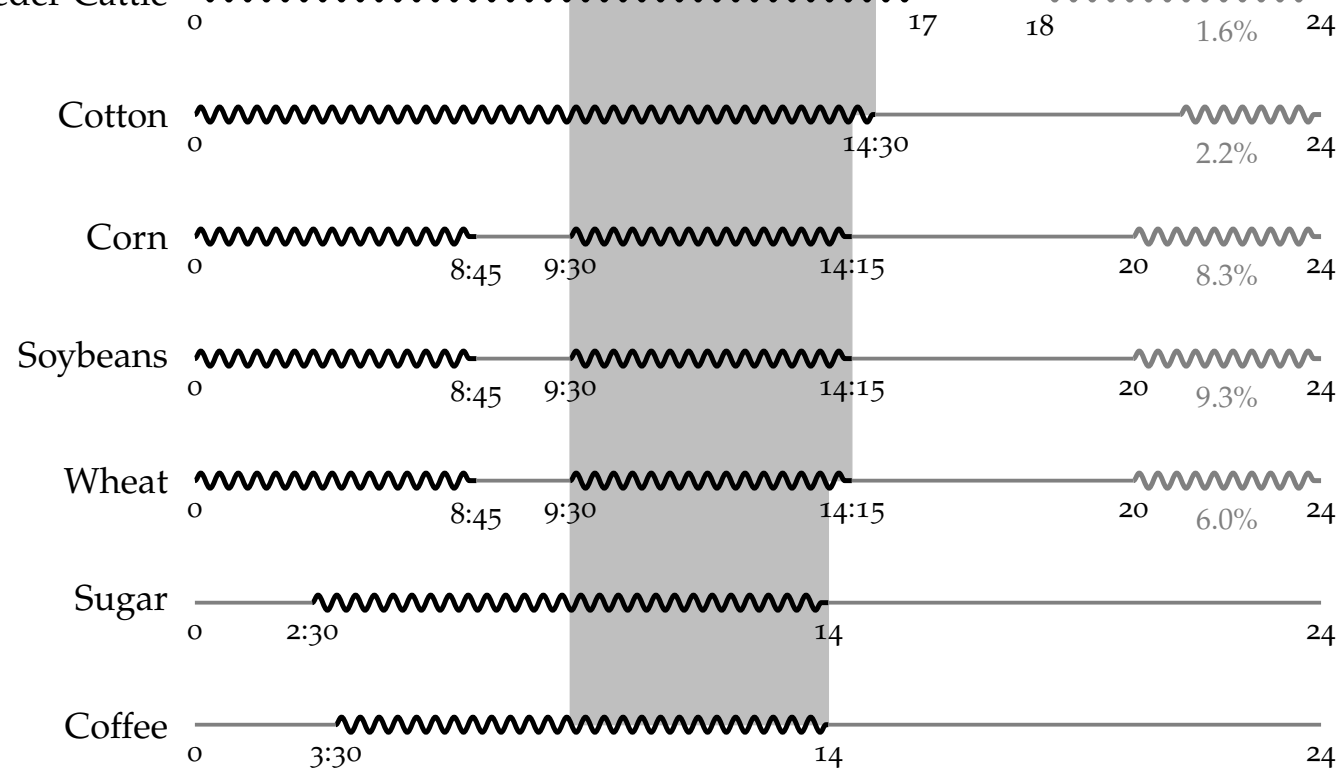

m Trading Span Interval used for $R C o v$

Wrading Span omitted for RVol__ Trading Break 
Figure 4: Autocorrelation Function of Daily Log-Realized Volatility.
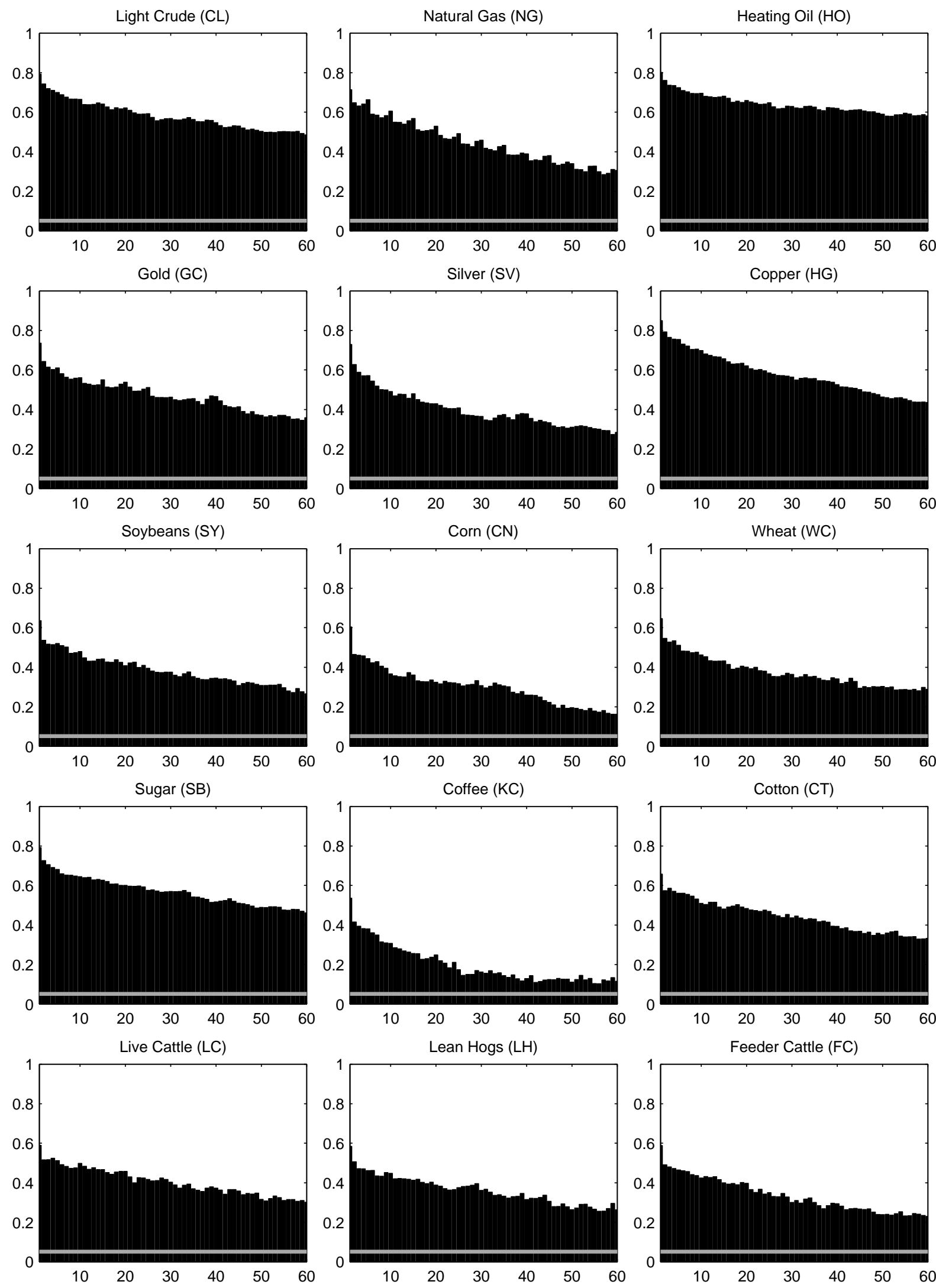

Notes: The grey line indicates the upper bound on the $99 \%$ confidence interval under the assumption that the series are Gaussian white noise. The horizontal axis indicates the lag order in trading days. 
Figure 5: QQ-Plot of Daily Log-Realized Volatility.
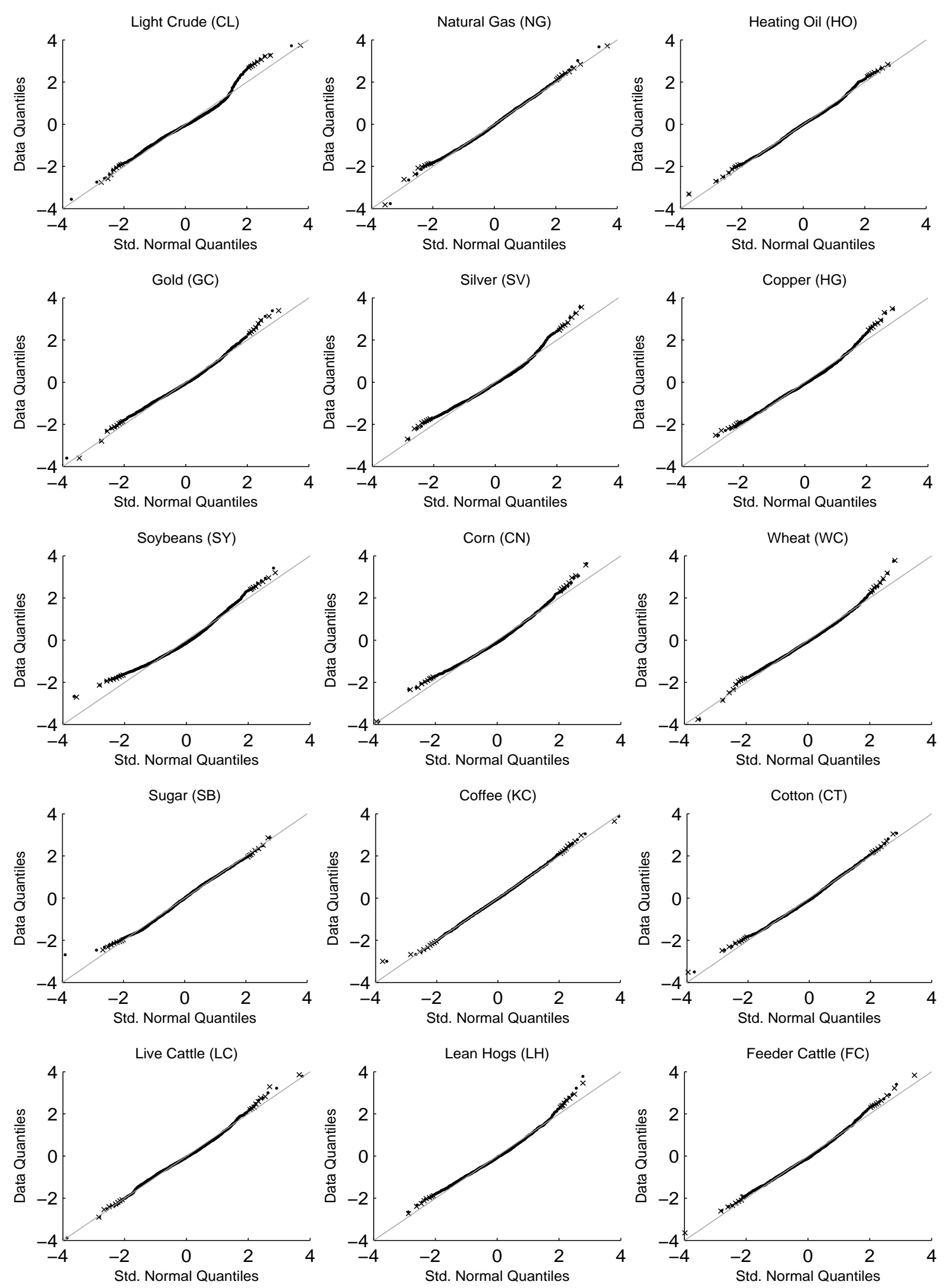

Notes: All observations are marked by dots. Crosses indicate large quantiles that do not correspond to rollover returns. 
Figure 6: Daily Expected Log-Realized Volatility.
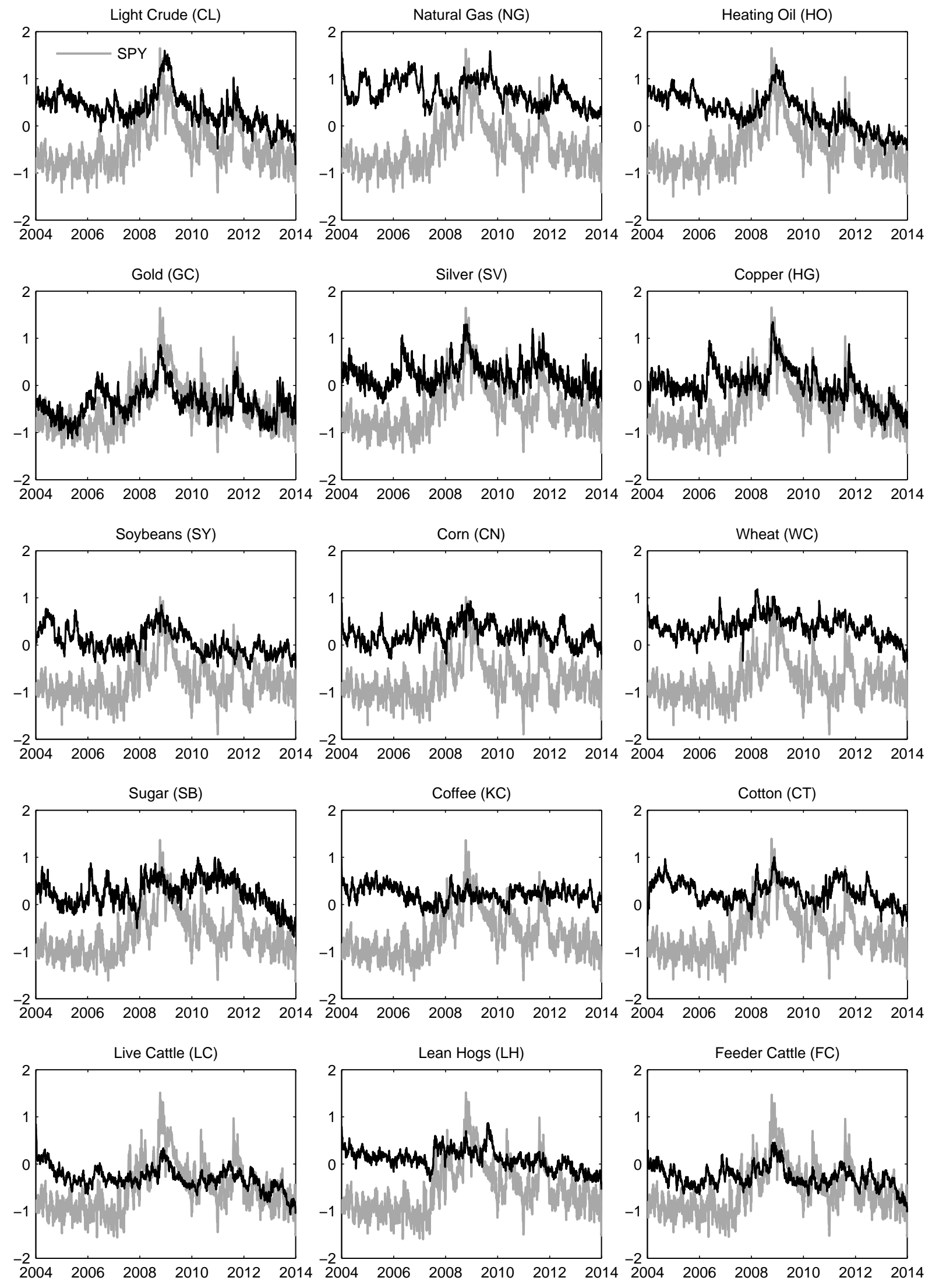
Figure 7.a: First Principal Component of Log-Returns. Cumulative Sum.
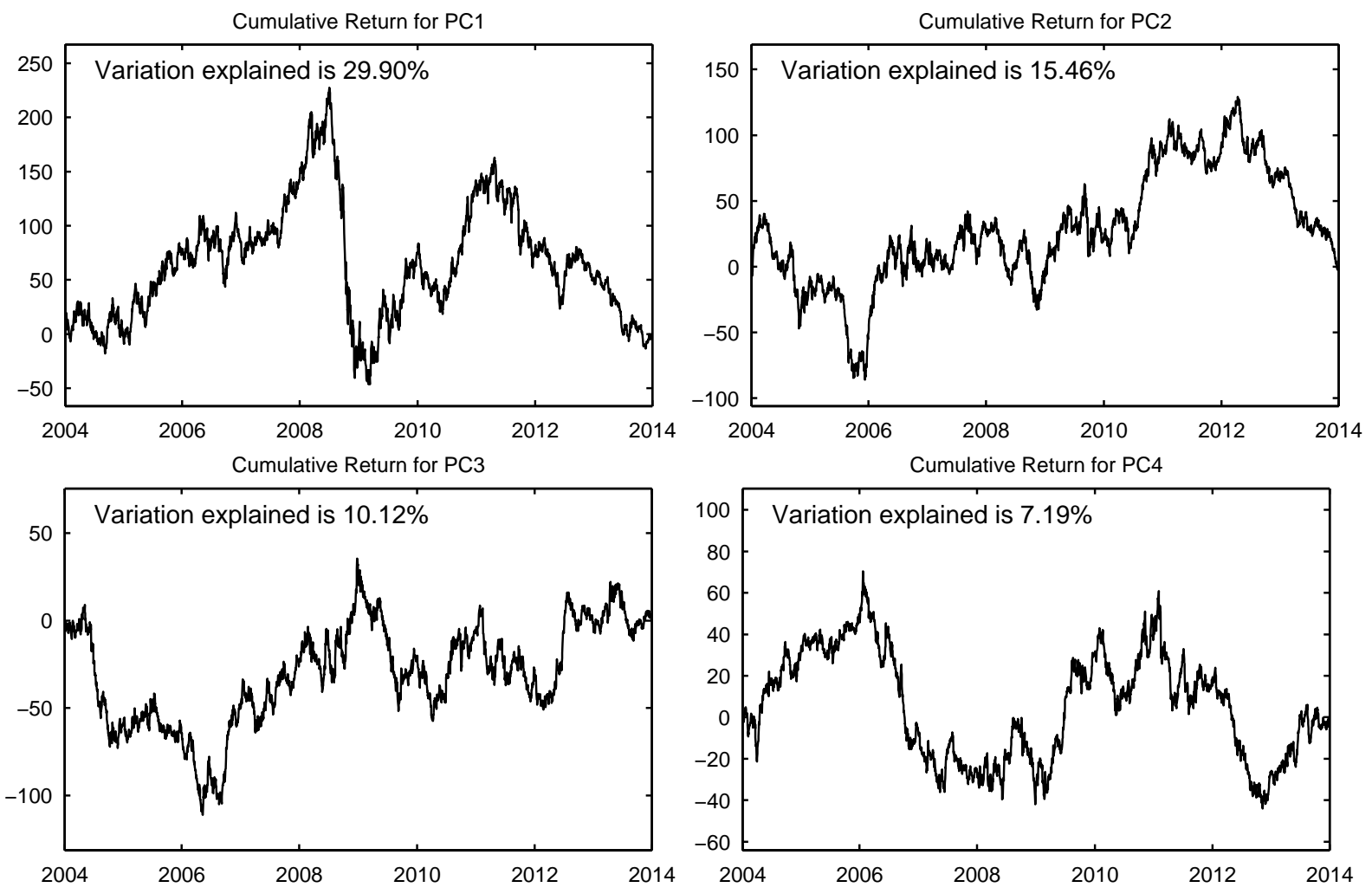

Figure 7.b: First Principal Component of Log-Realized Volatility.
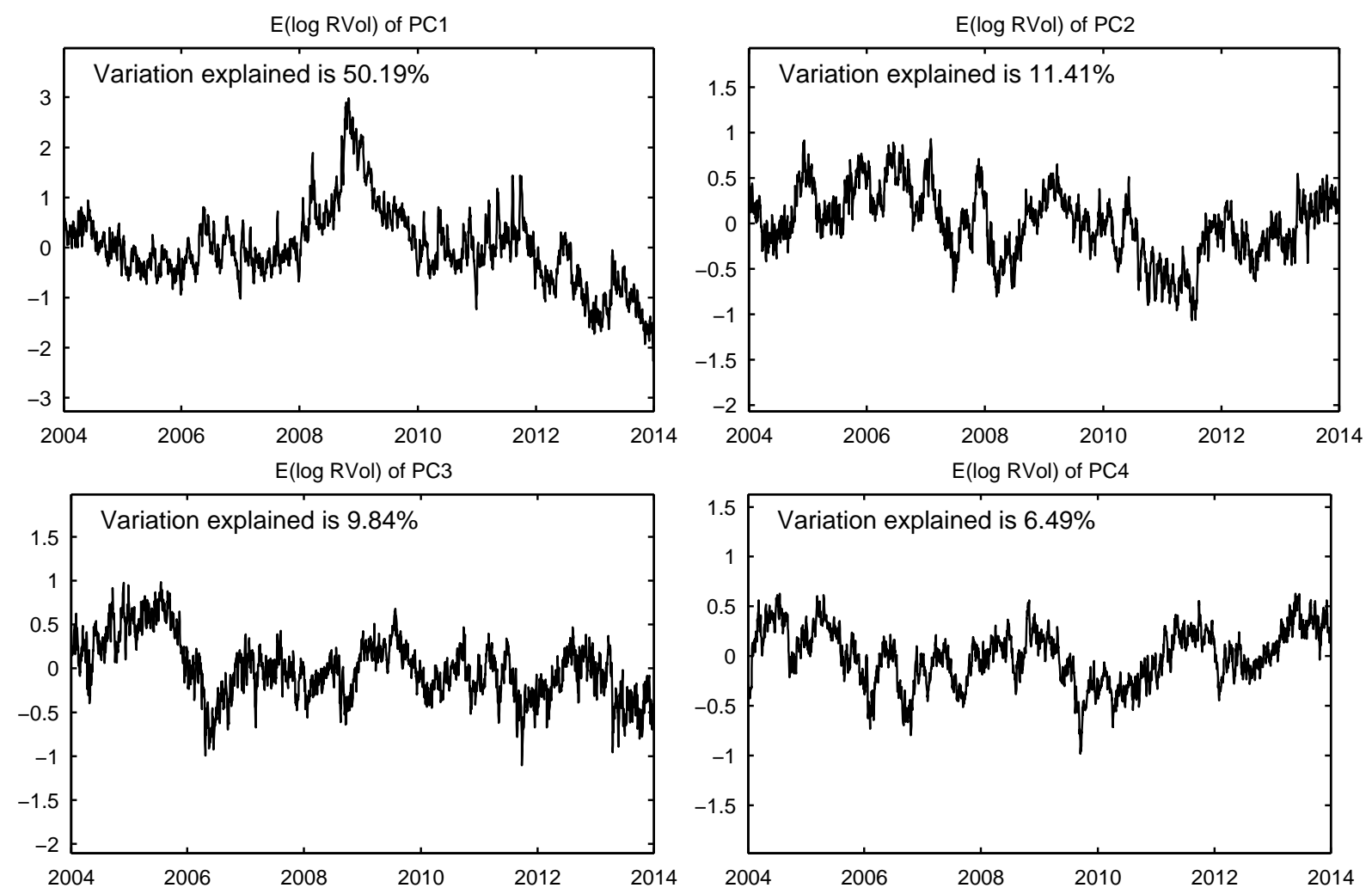
Figure 8: Time-Varying Market Integration in Returns and Volatility.
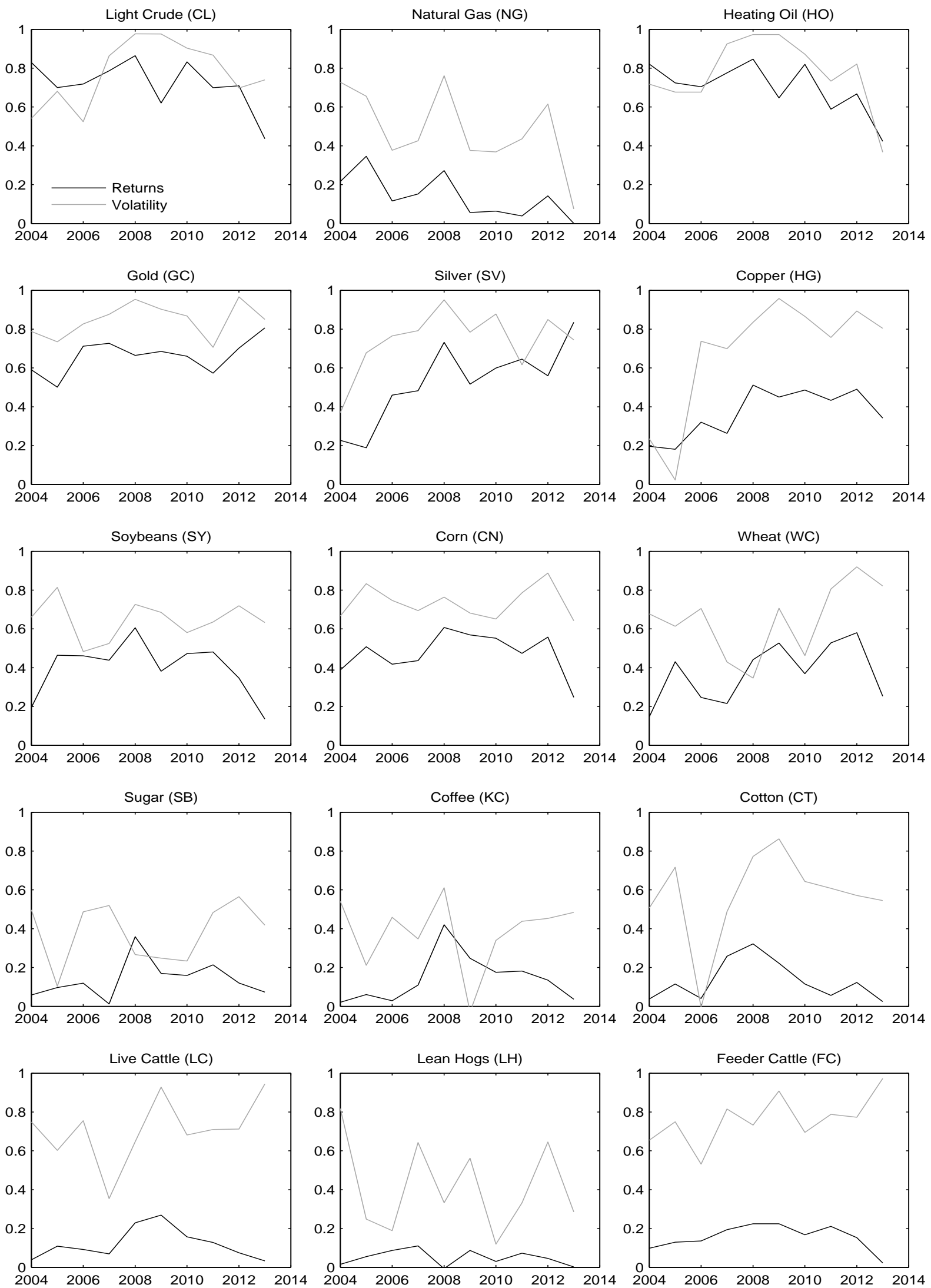
Figure 9: Expected Daily Beta with the Stock Market.
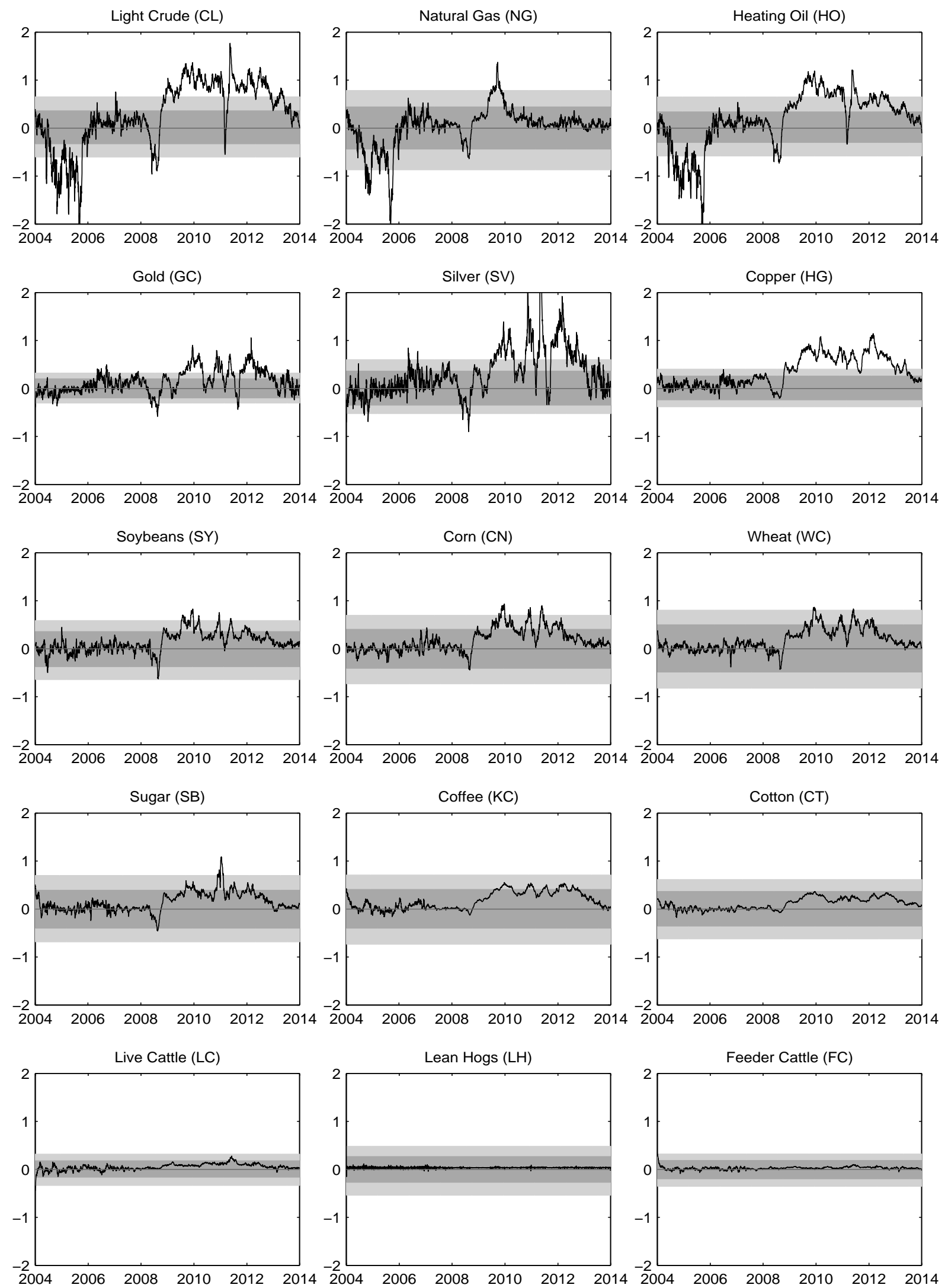

Notes: The shaded areas denote $75 \%$ (light grey) and $90 \%$ (dark grey) bootstrapped confidence intervals for the stock market betas. 
Figure 10: Expected Stock Market Systematic Risk Ratio for 15 Commodities.
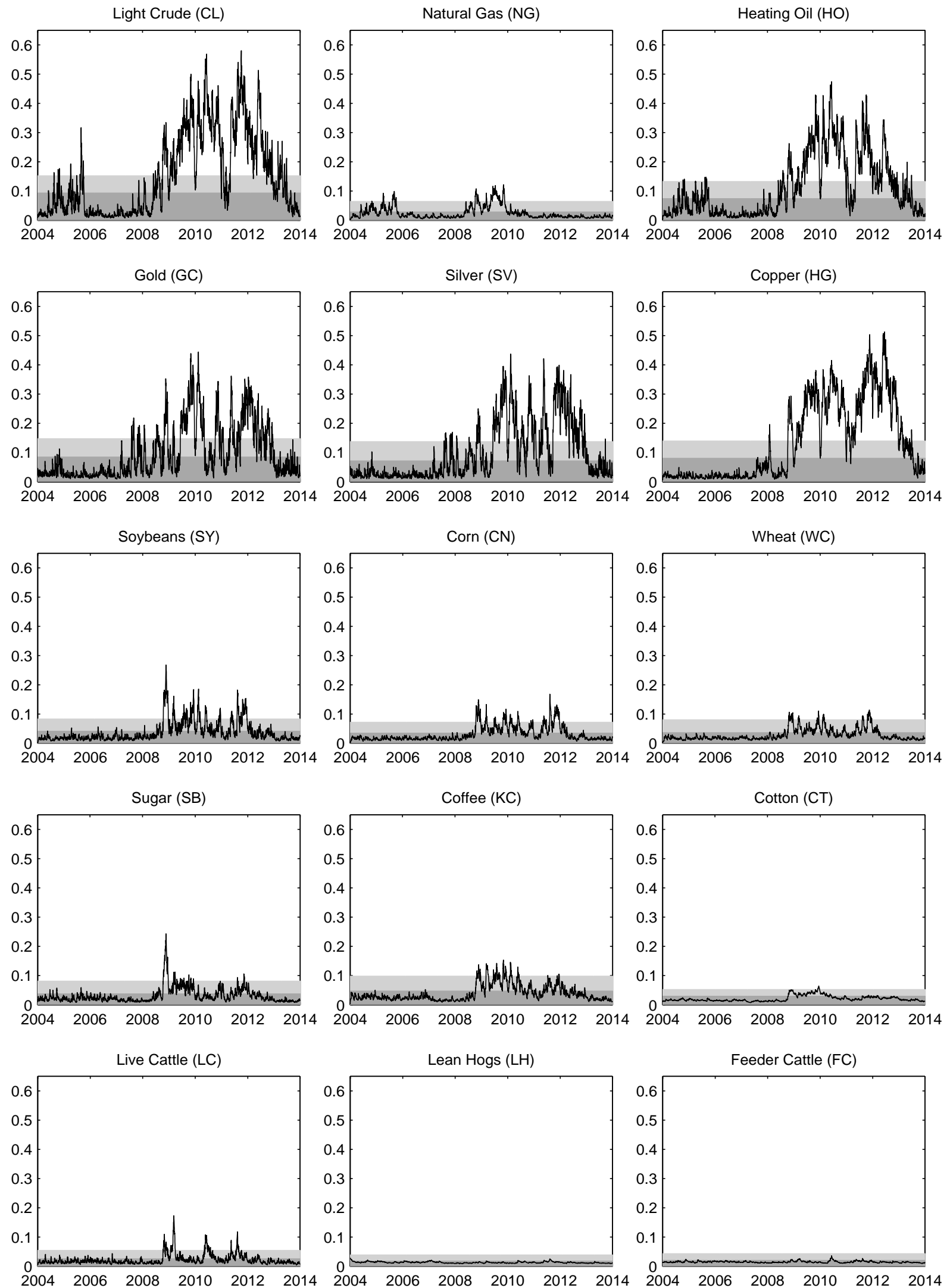

Notes: The shaded areas denote 75\% (light grey) and 90\% (dark grey) bootstrapped confidence intervals for the systematic risk ratio. 
Figure 11: Threshold Correlation Between Commodity and Stock Market Returns.
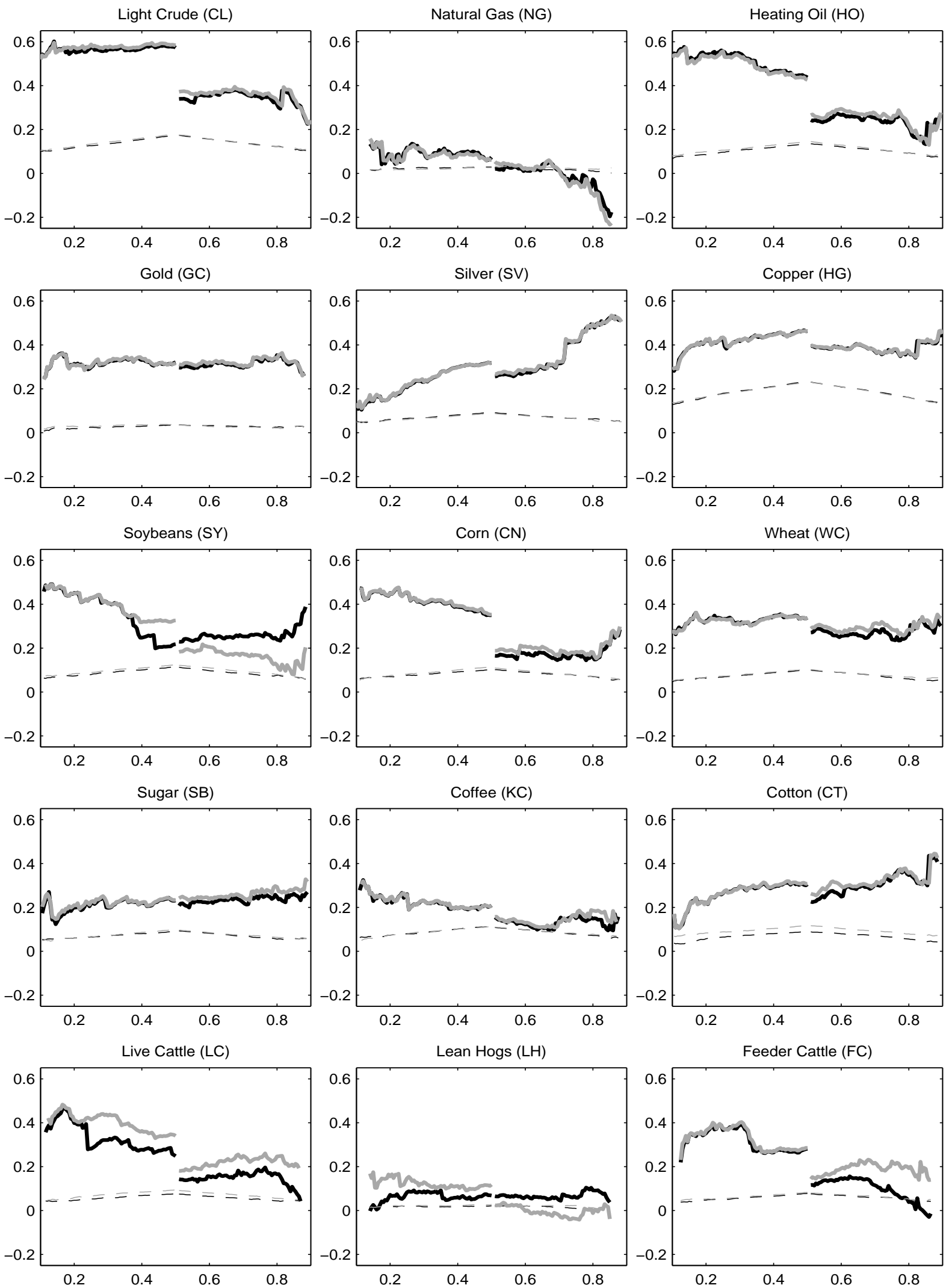

Notes: Threshold correlations with rollover days included (black lines) and with rollover days excluded (grey lines). The dashed lines denote threshold correlations for the bivariate Gaussian distribution. 
Figure 12: Threshold Correlation Between Expected Log Realized Volatility for Spyder and 15 Commodities.
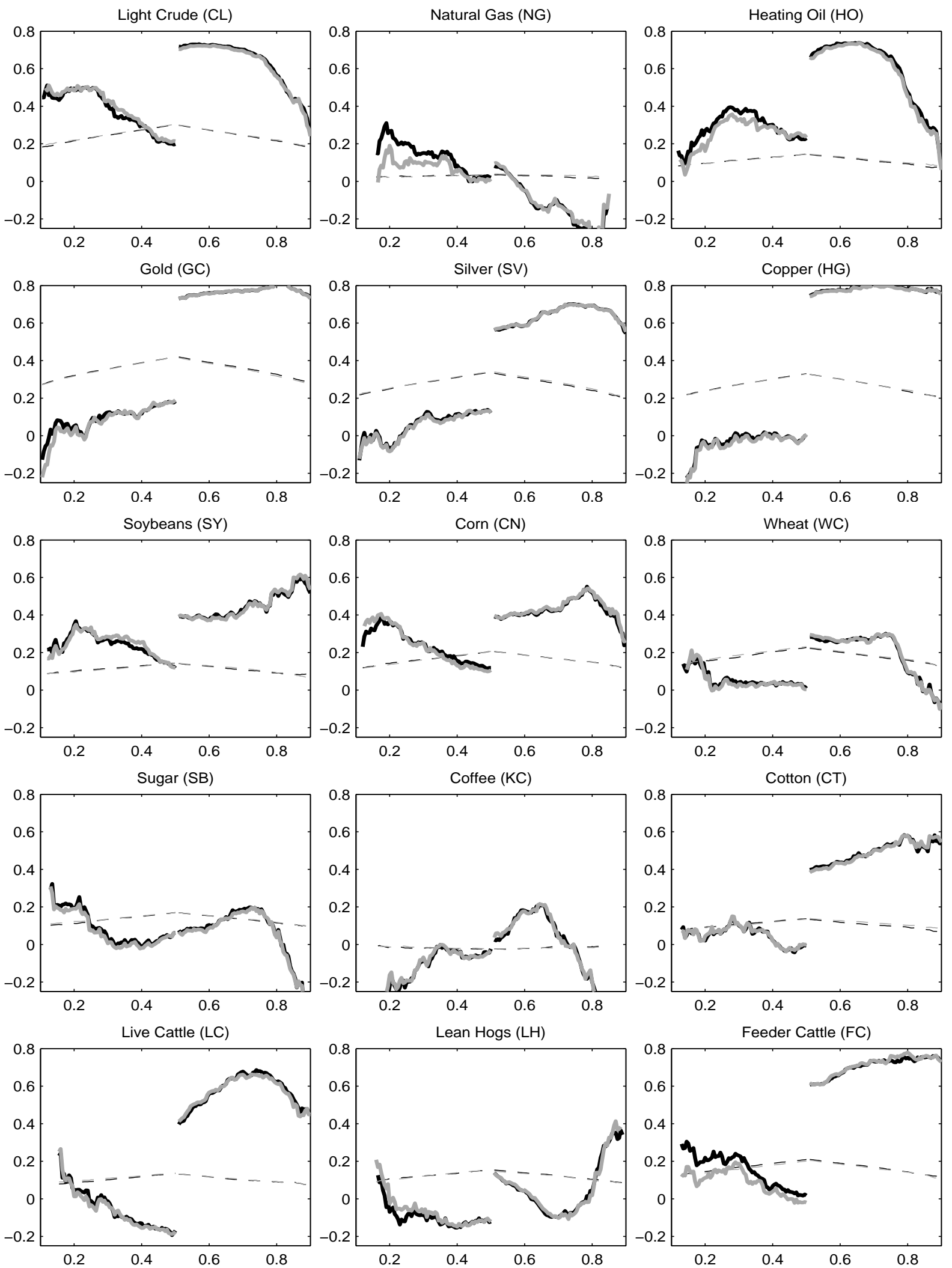

Notes: Threshold correlations with rollover days included (black lines) and with rollover days excluded (grey lines). The dashed lines denote threshold correlations for the bivariate Gaussian distribution. The horizontal axis indicates thresholds in percentiles. 
Figure 13: QQ-Plot of Daily Return Shocks.
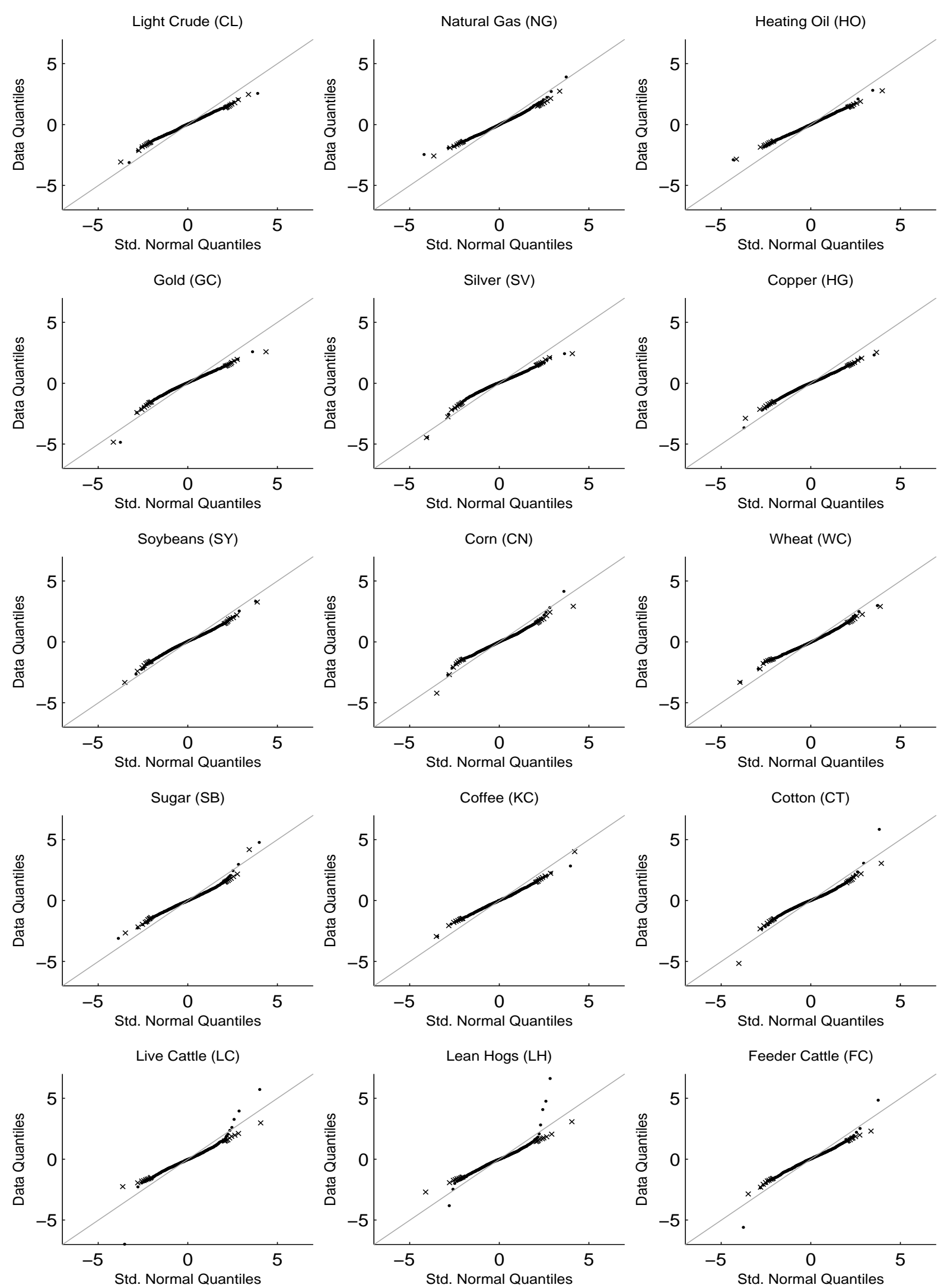

Notes: All observations are marked by dots. Crosses indicate large quantiles that do not correspond to rollover returns. 


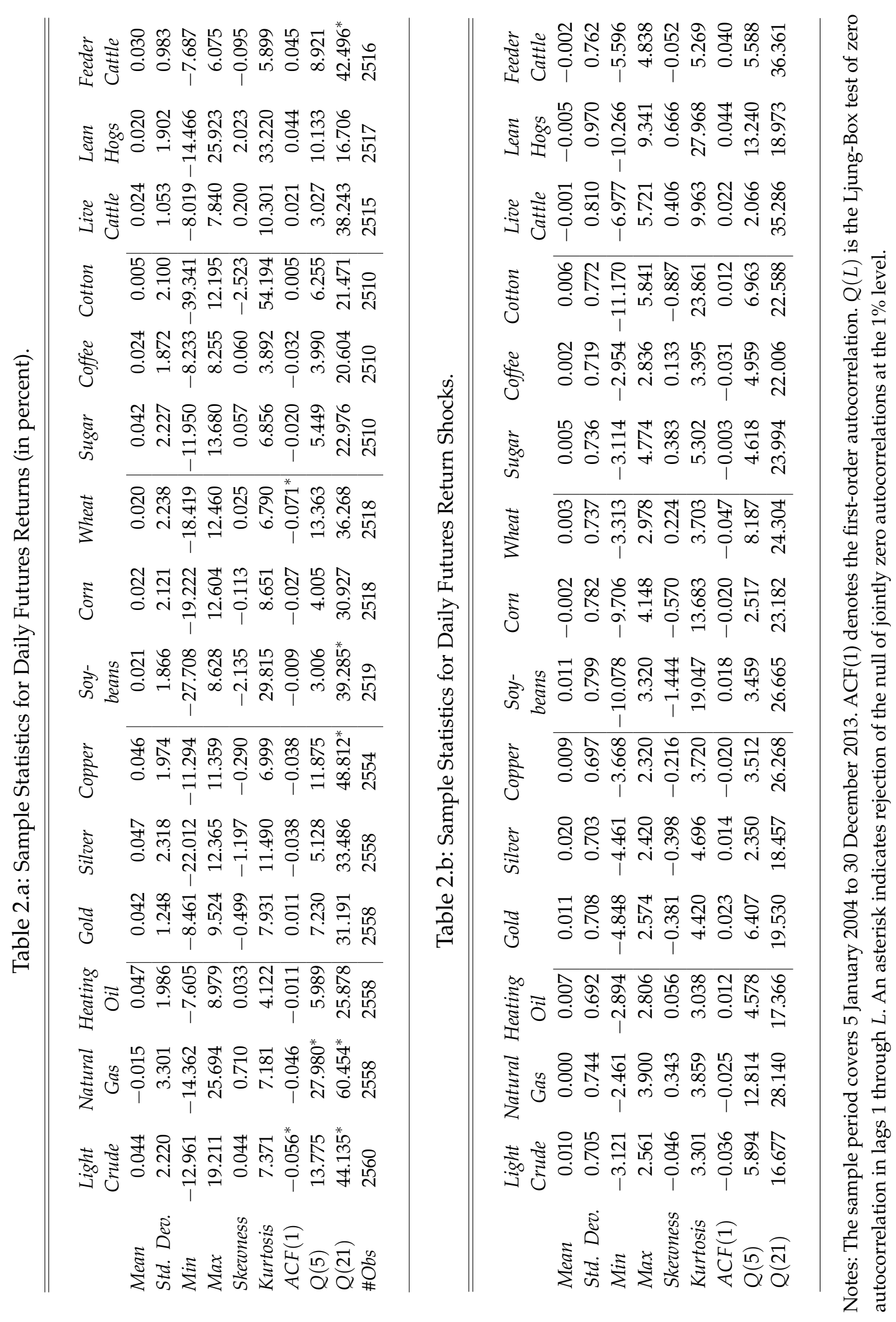




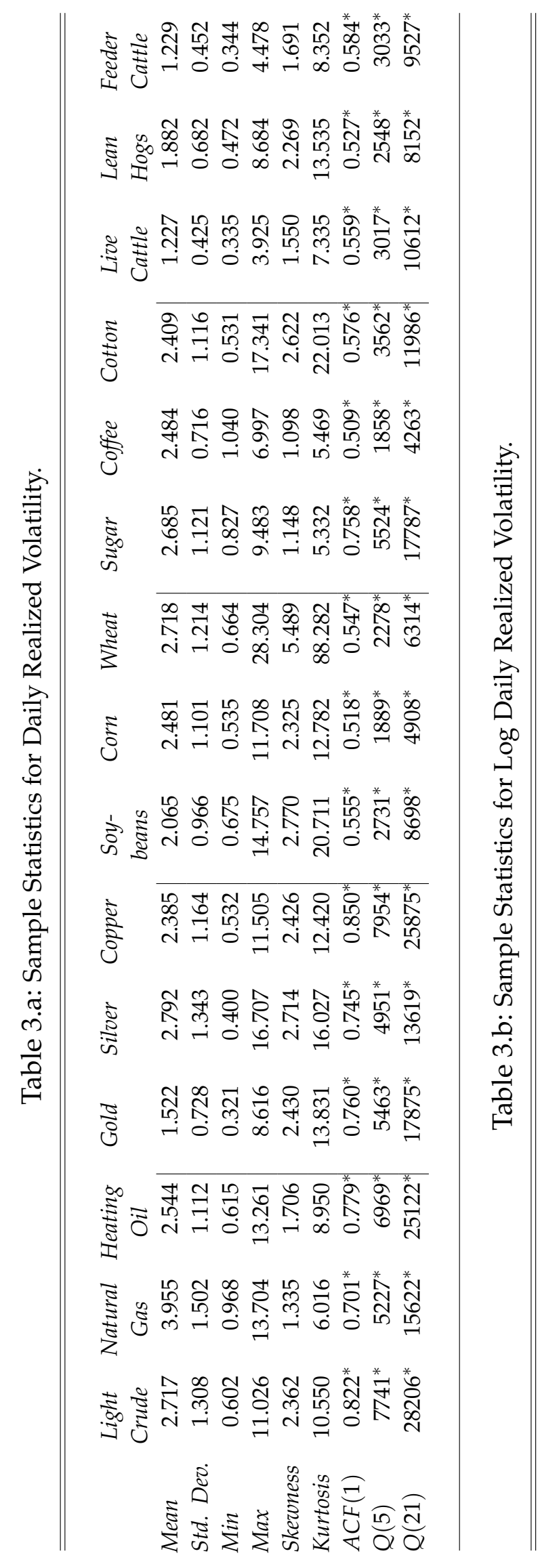

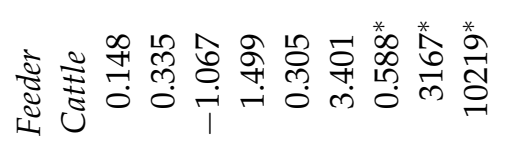

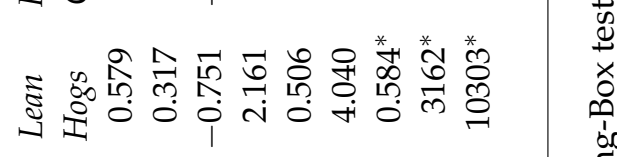

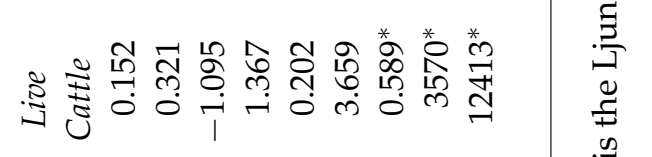

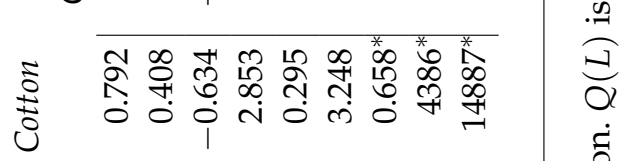

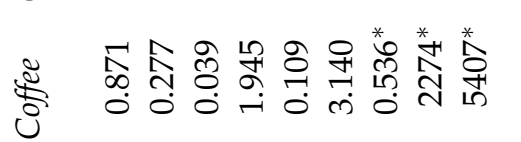

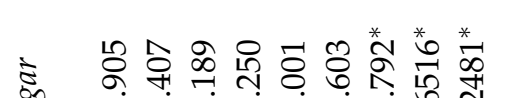

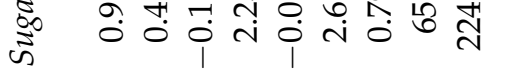

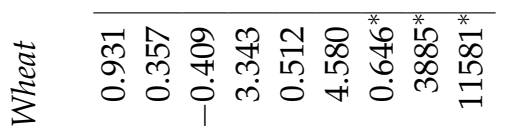

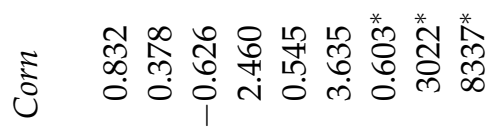

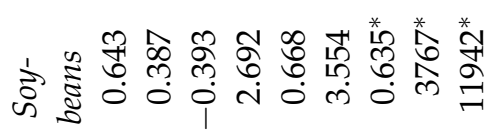

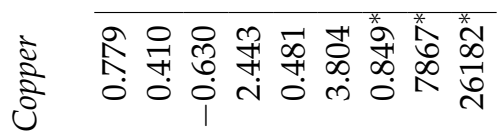

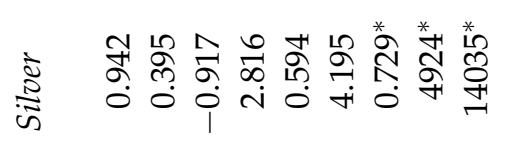

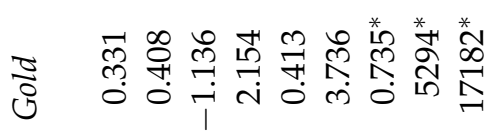

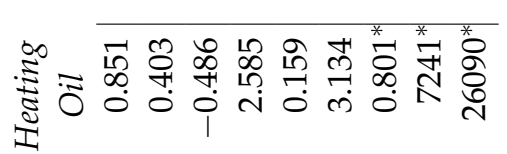

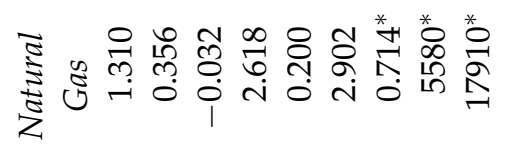

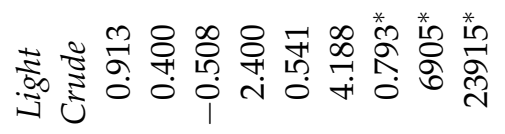

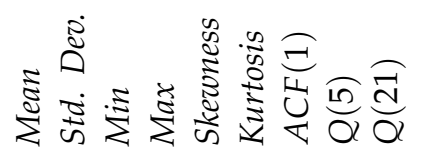

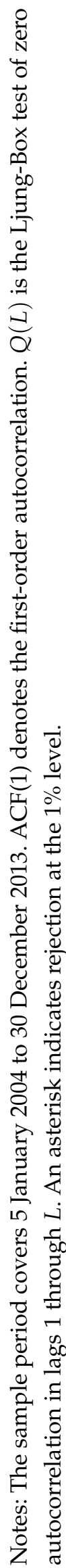




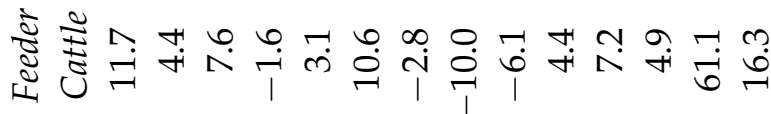

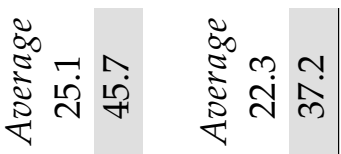

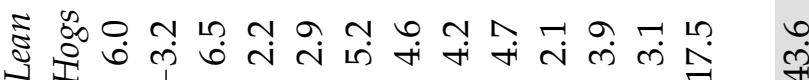

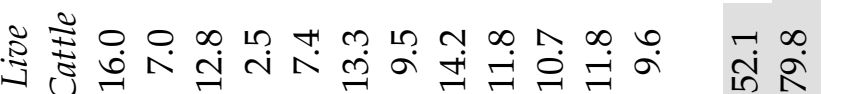

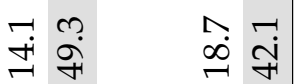

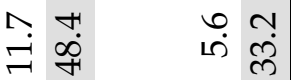

ڤิن

产

ํํㄹำ

苂

m. म

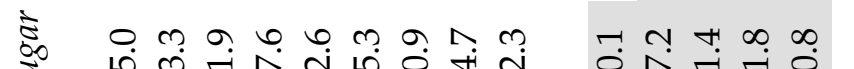

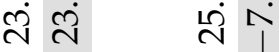

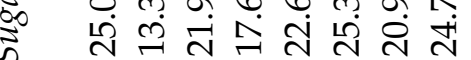

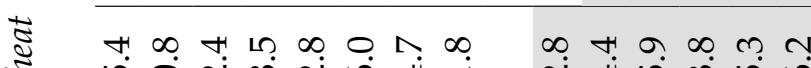

$\infty-1 \quad 0$

तें

ร

H.

ลิ่

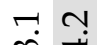

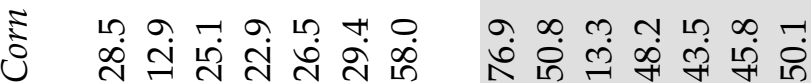

$n$ L 100

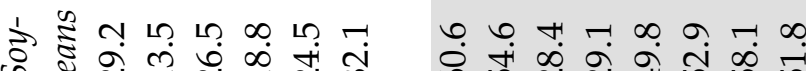

ลे

वृं अं

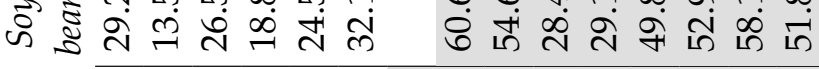

से

เก เก

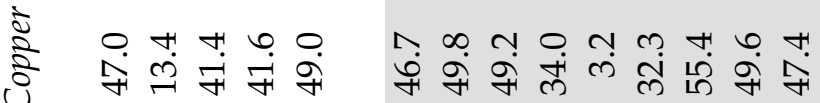

i

तें

$\vec{i}$ 의

N

过 寉

इ

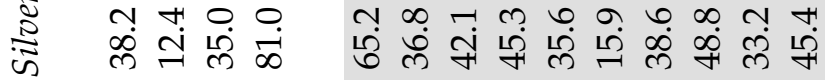

का

$\infty$

ํำ

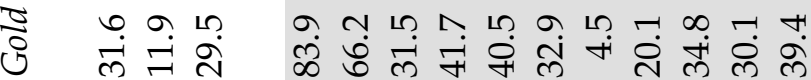

$\infty 0$

¿ุ่

ㄱำ

落

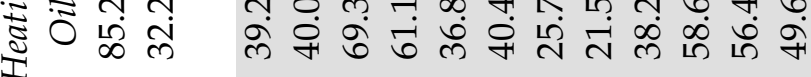

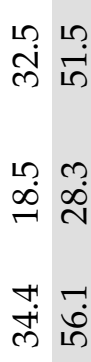

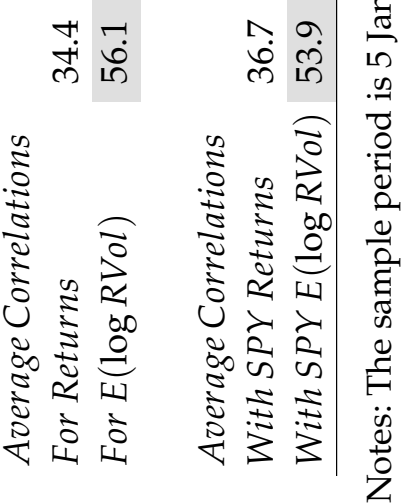

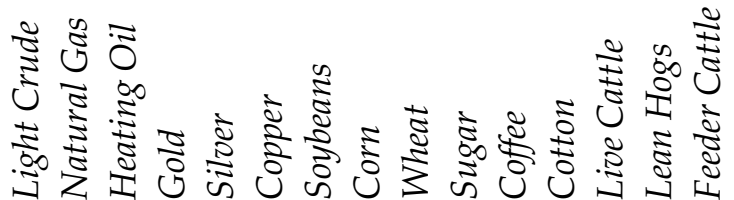

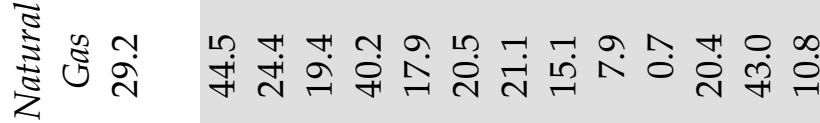

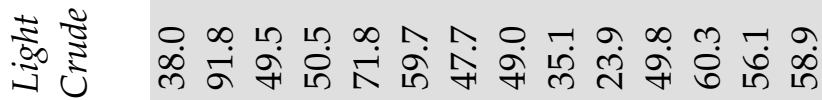

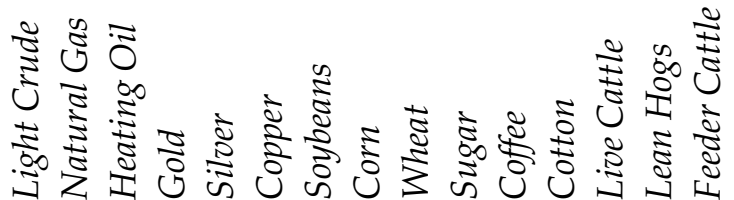




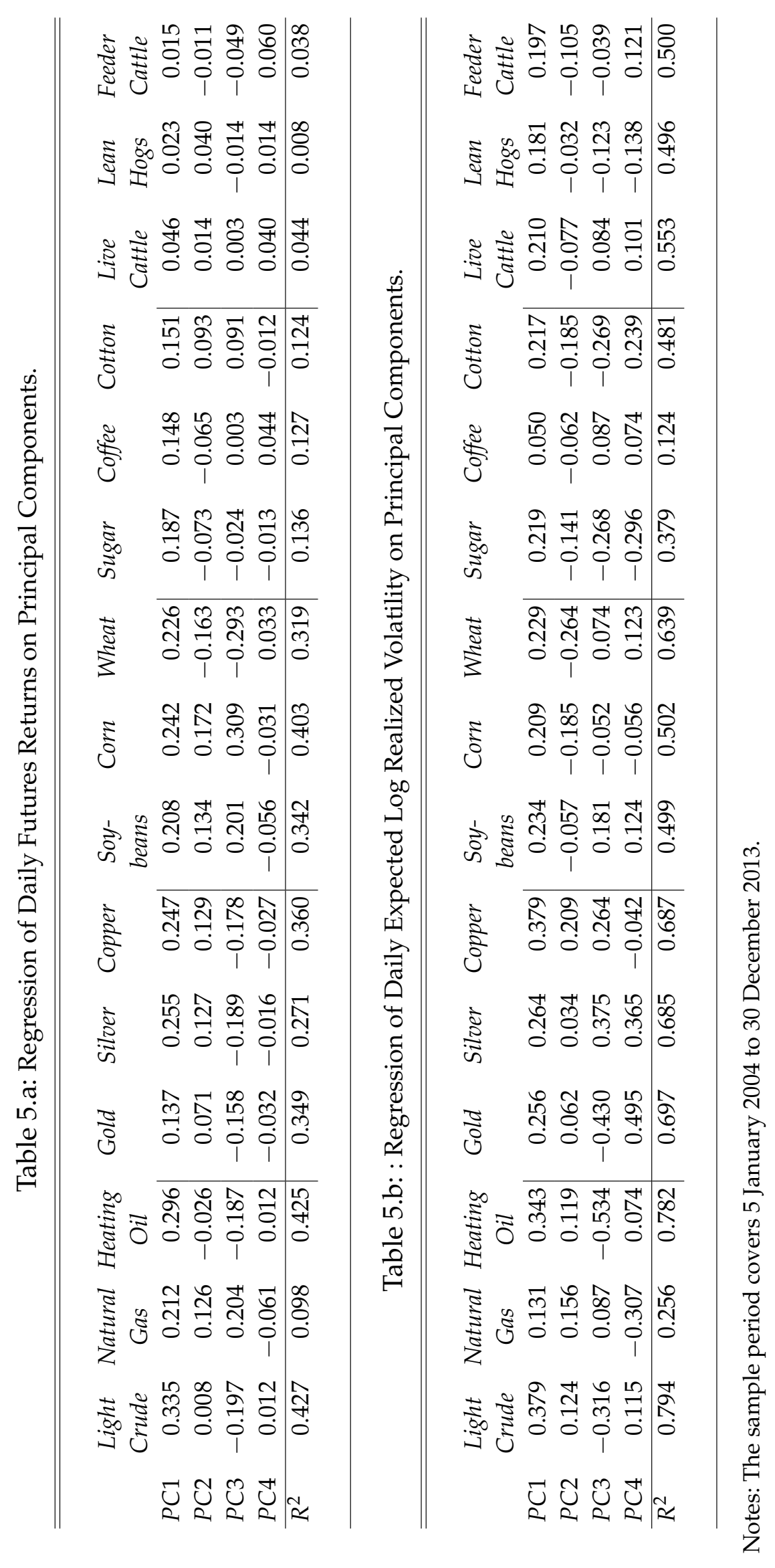




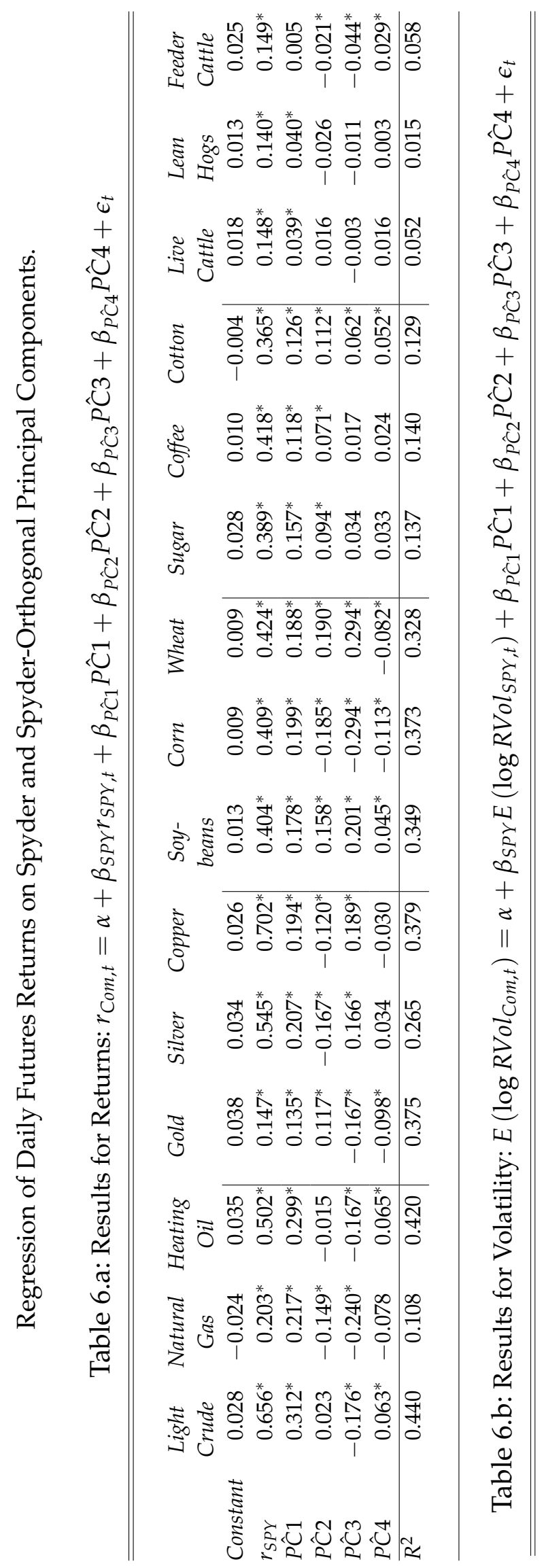

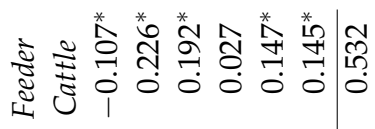

䒕 $\bar{\sigma}$.

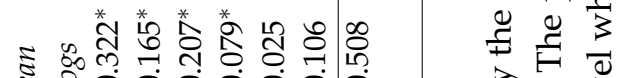

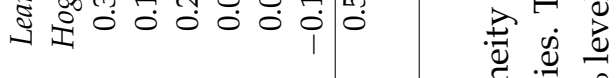

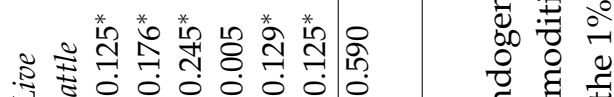

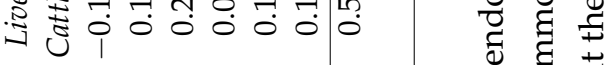

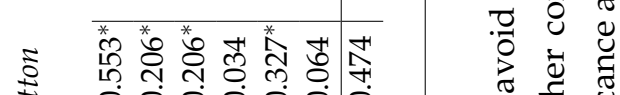

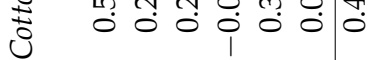

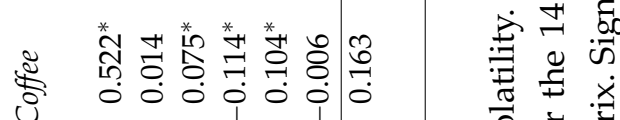

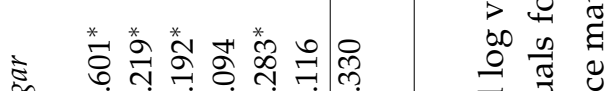

के 0.

童

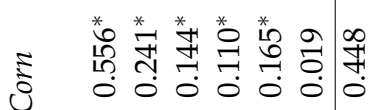

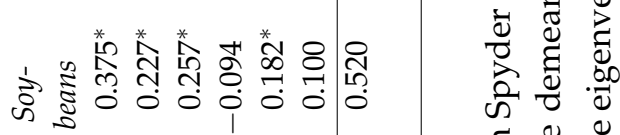

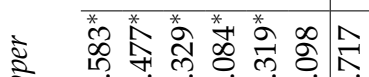

ᄃ

ఫृ

उ $0000 \% 0$

竎

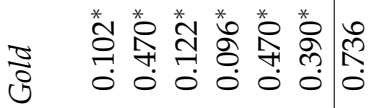

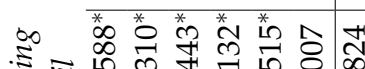

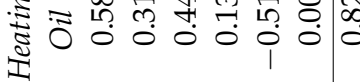

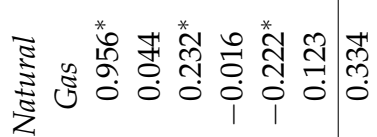

₹

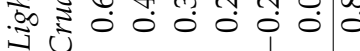

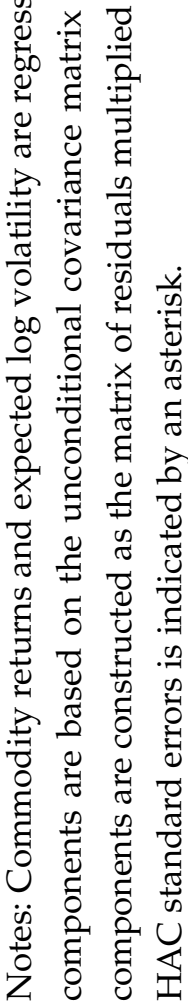




\section{Appendix}

Figure A.1: Daily Futures Returns.
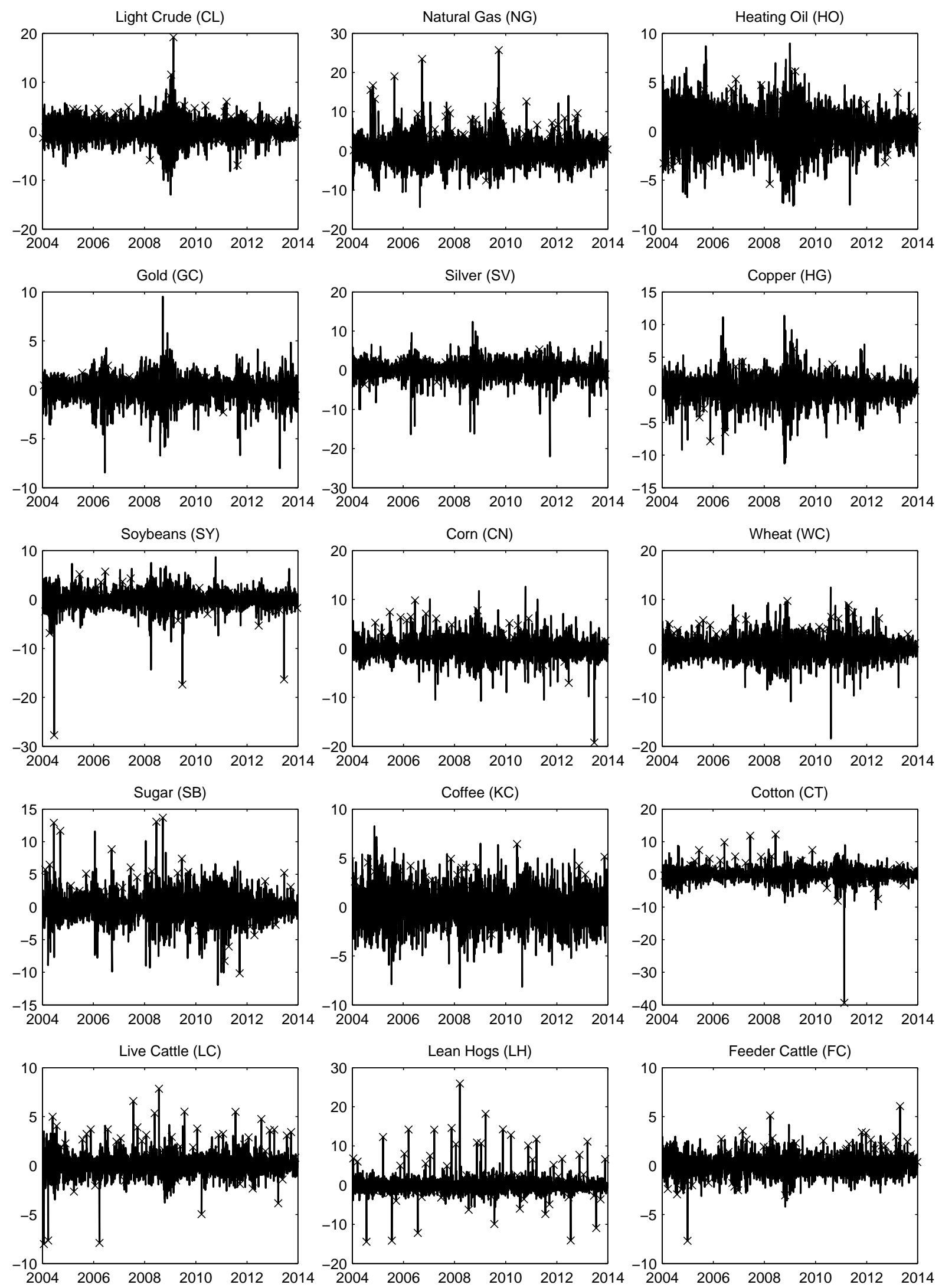

Notes: The crosses denote rollover days. 
Figure A.2: Autocorrelation Function of Daily Futures Returns.
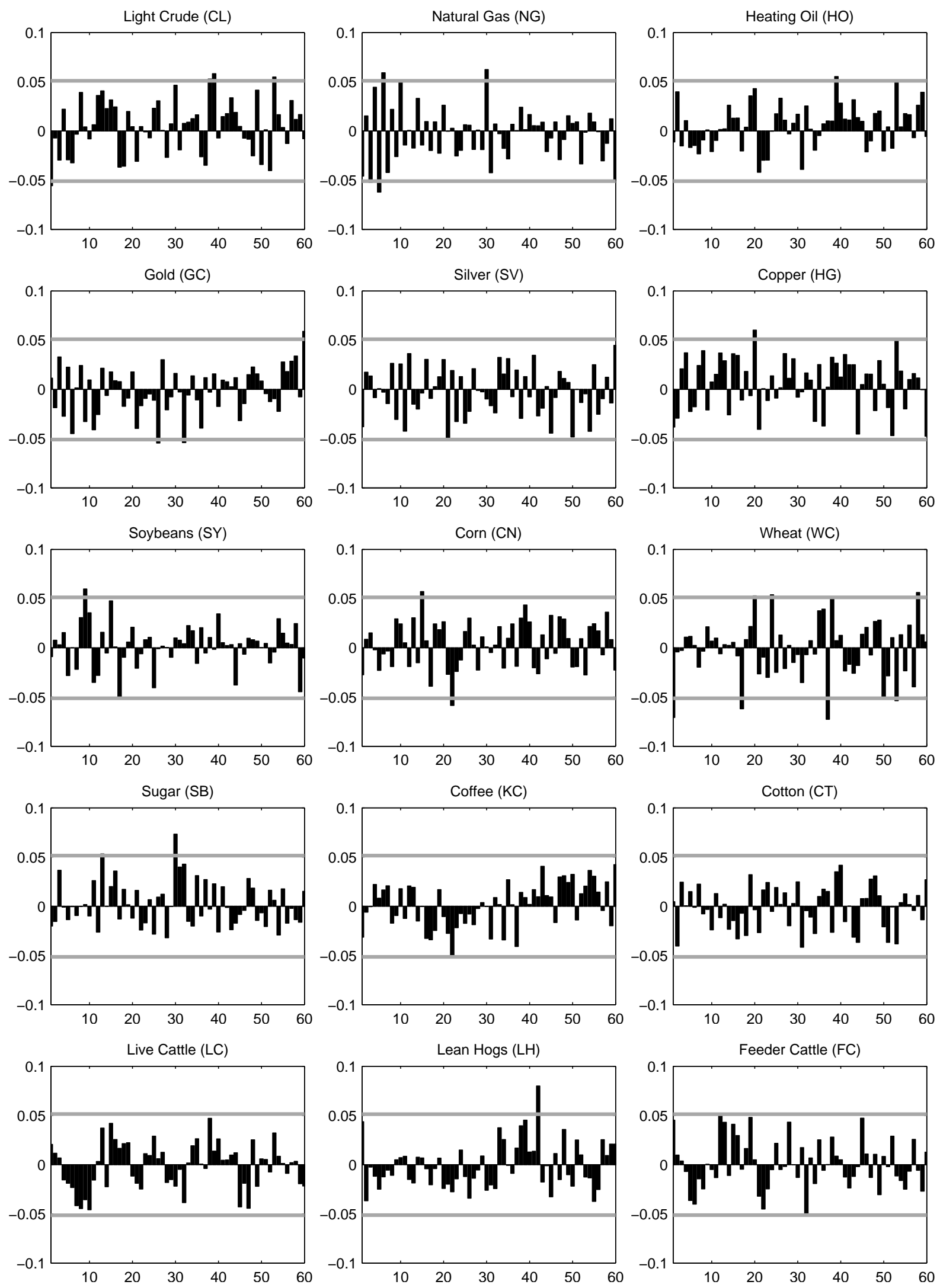

Notes: Grey lines indicate $99 \%$ confidence bounds assuming that the series are Gaussian white noise. The horizontal axis indicates the lag order in days.

48 
Figure A.3: Daily Realized Volatility.
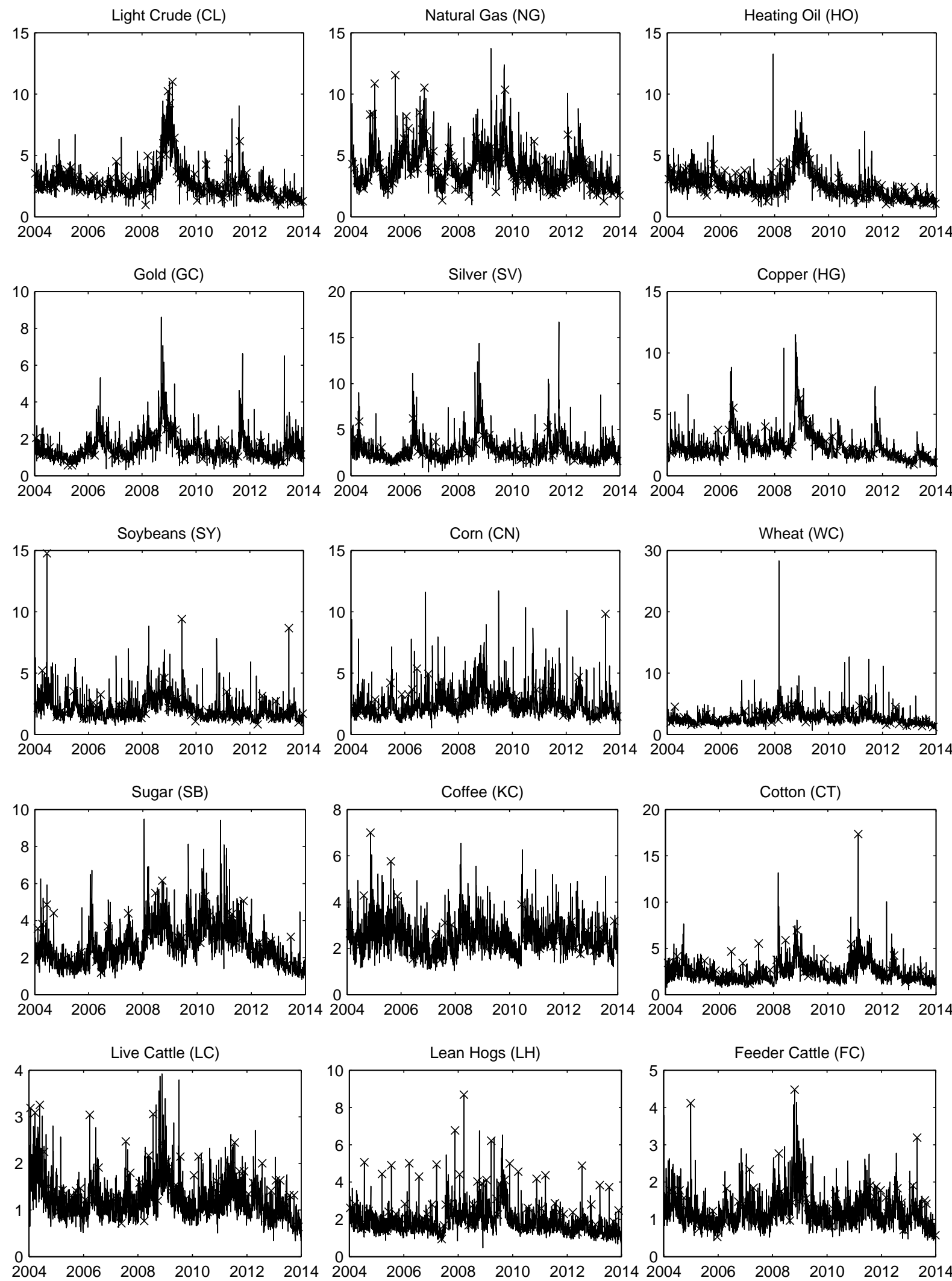

Notes: The crosses denote rollover days. 
Figure A.4: Daily Log-Realized Volatility.
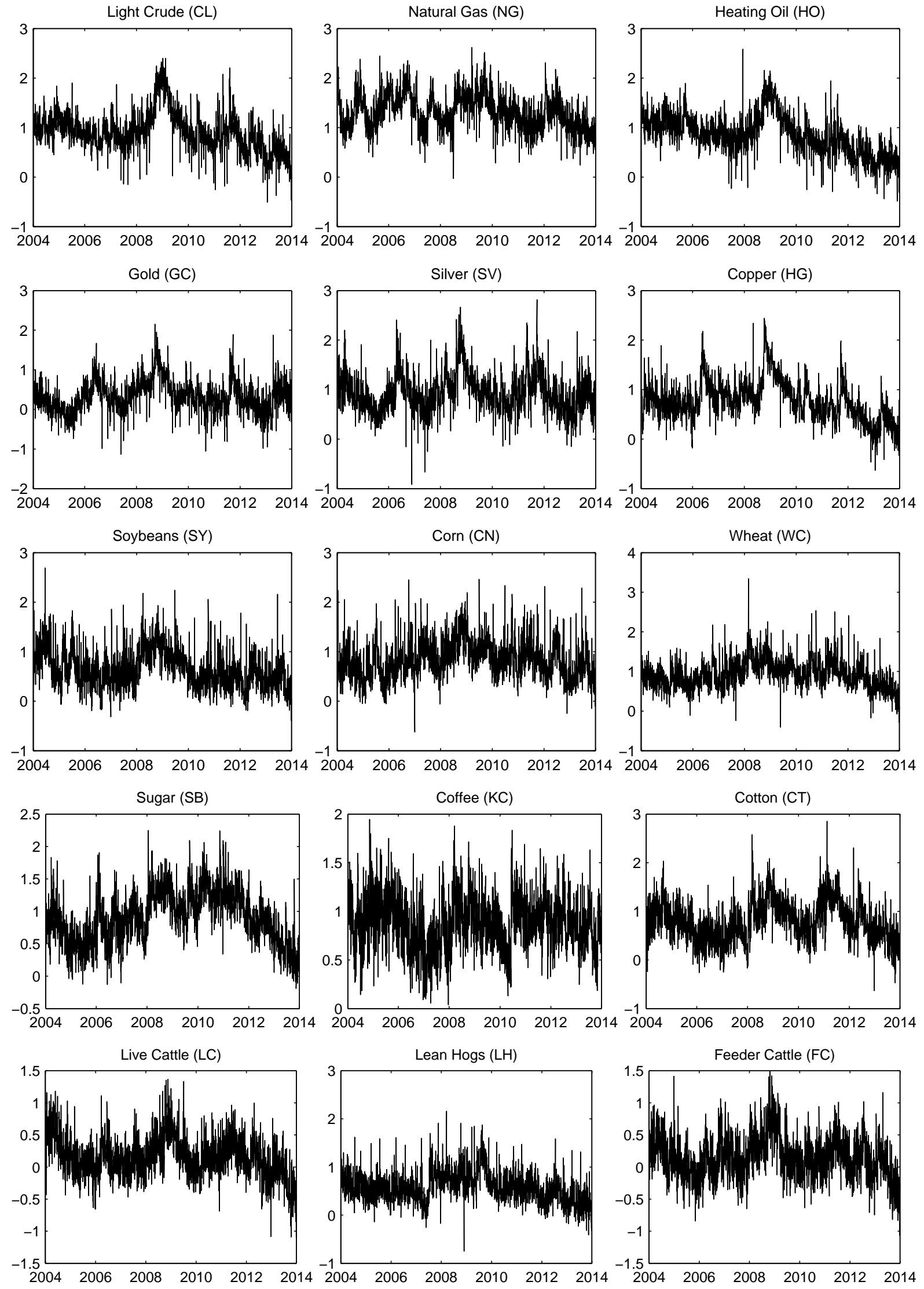
Figure A.5: Realized Stock Market Beta for 15 Commodities.
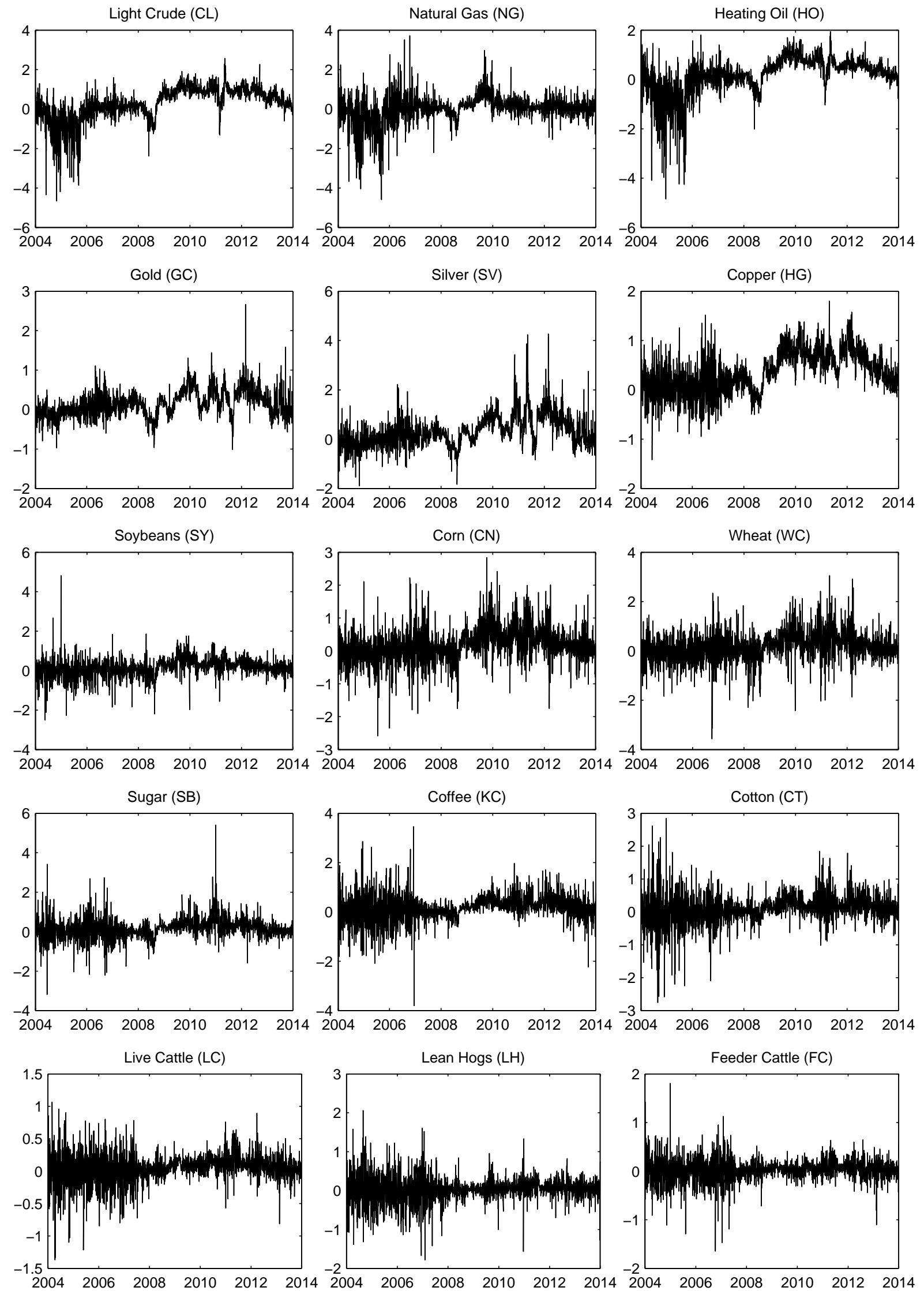
Figure A.6: QQ-Plots of Daily Futures Returns.

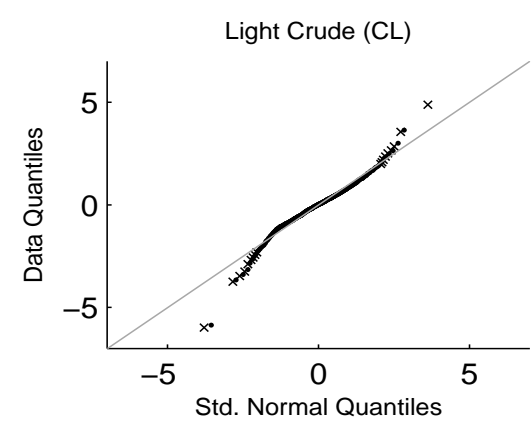

Gold (GC)

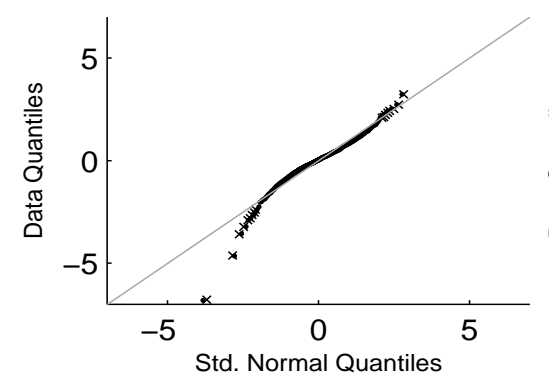

Soybeans (SY)

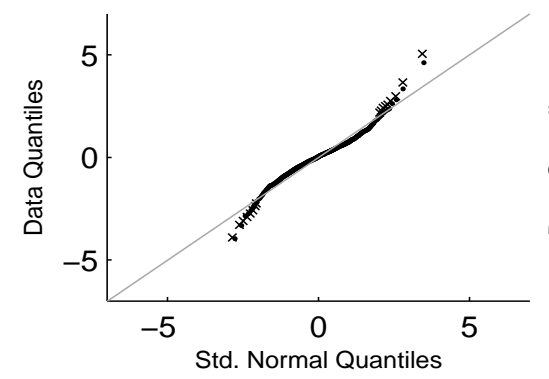

Sugar (SB)

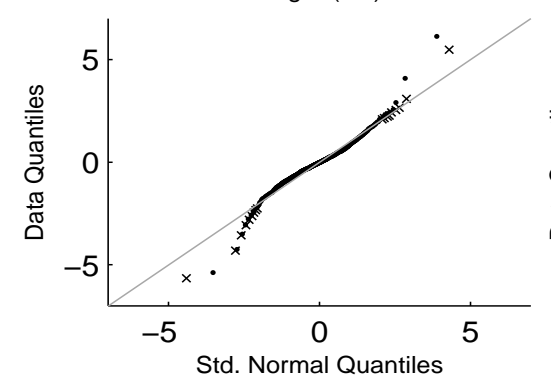

Live Cattle (LC)

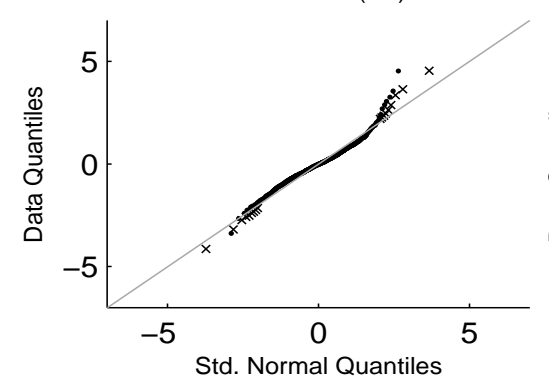

Natural Gas (NG)

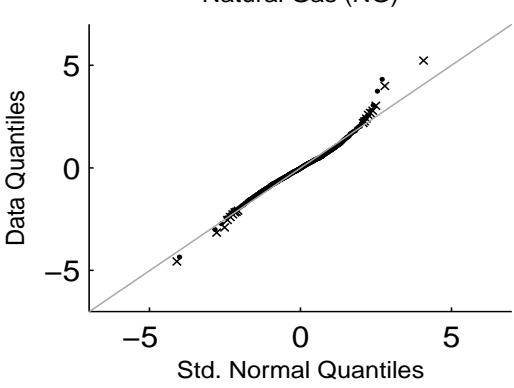

Silver (SV)

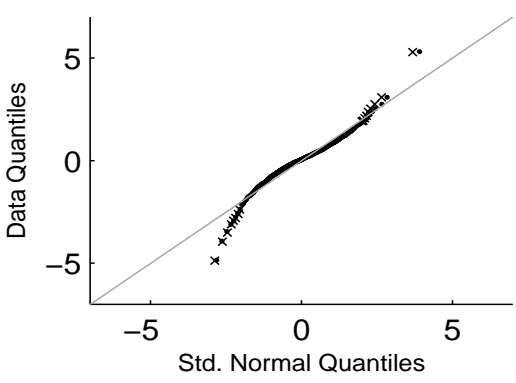

Corn $(\mathrm{CN})$

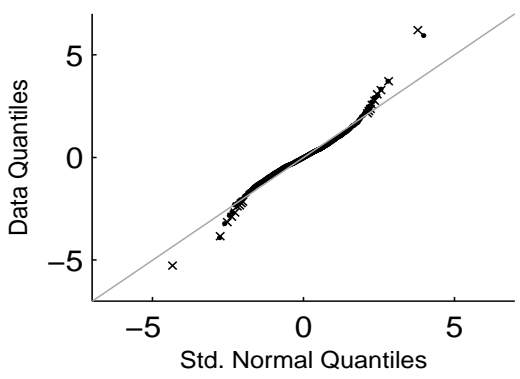

Coffee (KC)

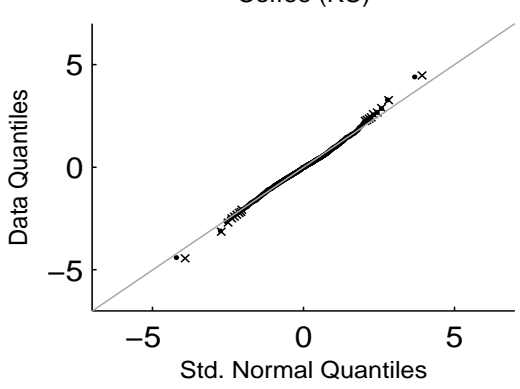

Lean Hogs (LH)

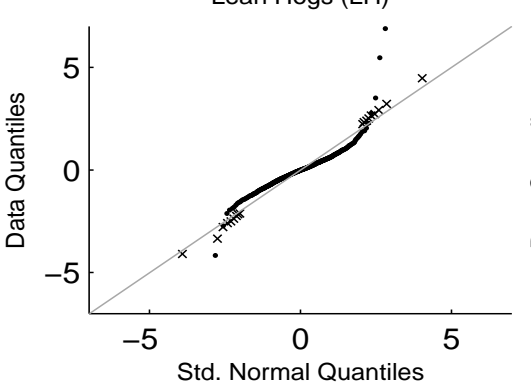

Heating Oil $(\mathrm{HO})$

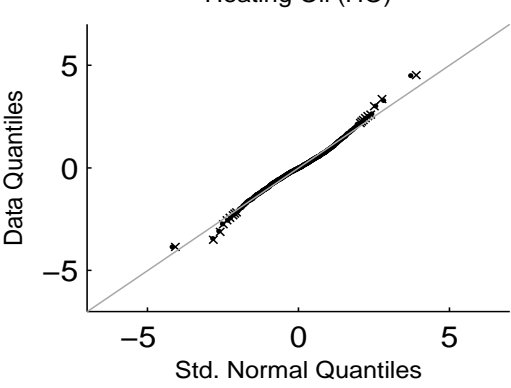

Copper (HG)

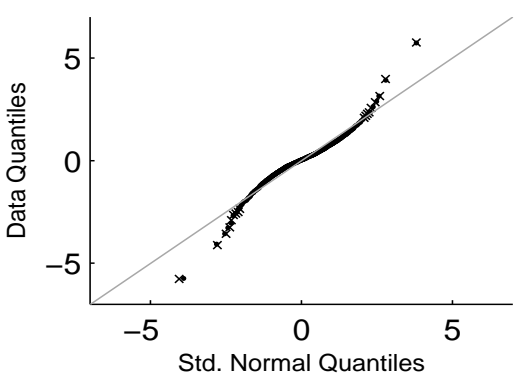

Wheat (WC)

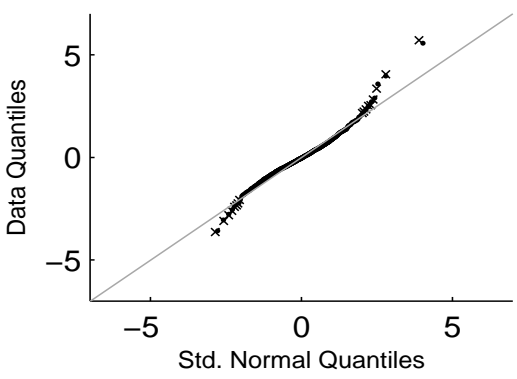

Cotton (CT)

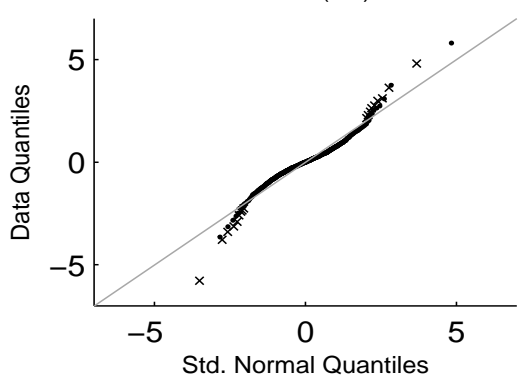

Feeder Cattle (FC)

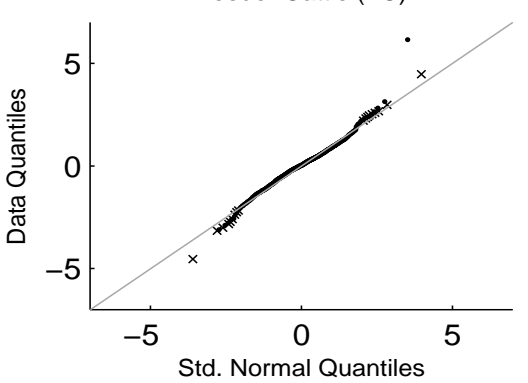

Notes: All observations are marked by dots. Crosses indicate large quantiles that do not correspond to rollover returns. 
Figure A.7: Threshold Correlation Between Daily Commodity Return Shocks and Spyder.
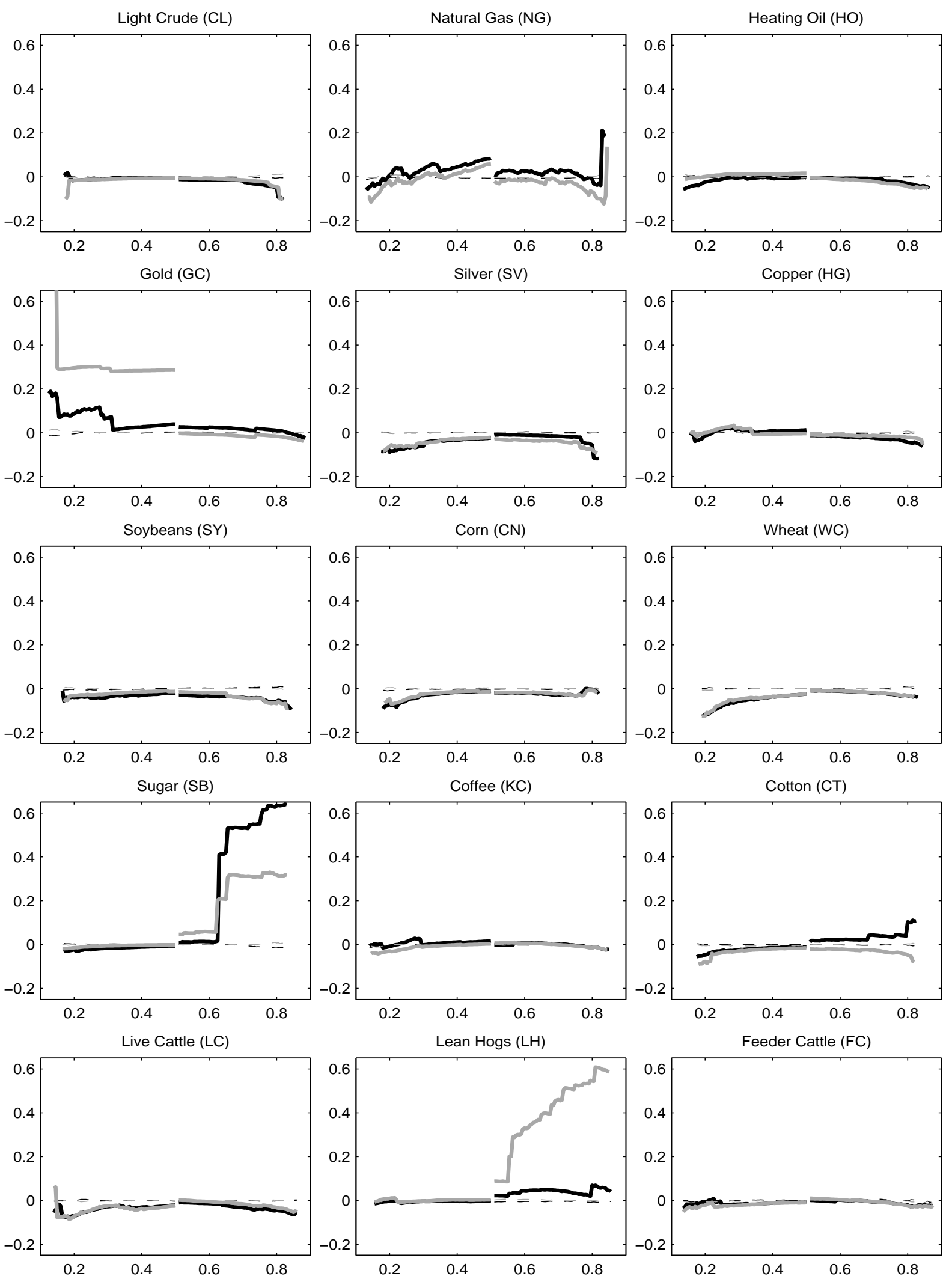

Notes: Threshold correlations with rollover days included (black lines) and with rollover days excluded (grey lines). The dashed lines denote threshold correlations for the bivariate Gaussian distribution. The horizontal axis indicates thresholds in percentiles. 


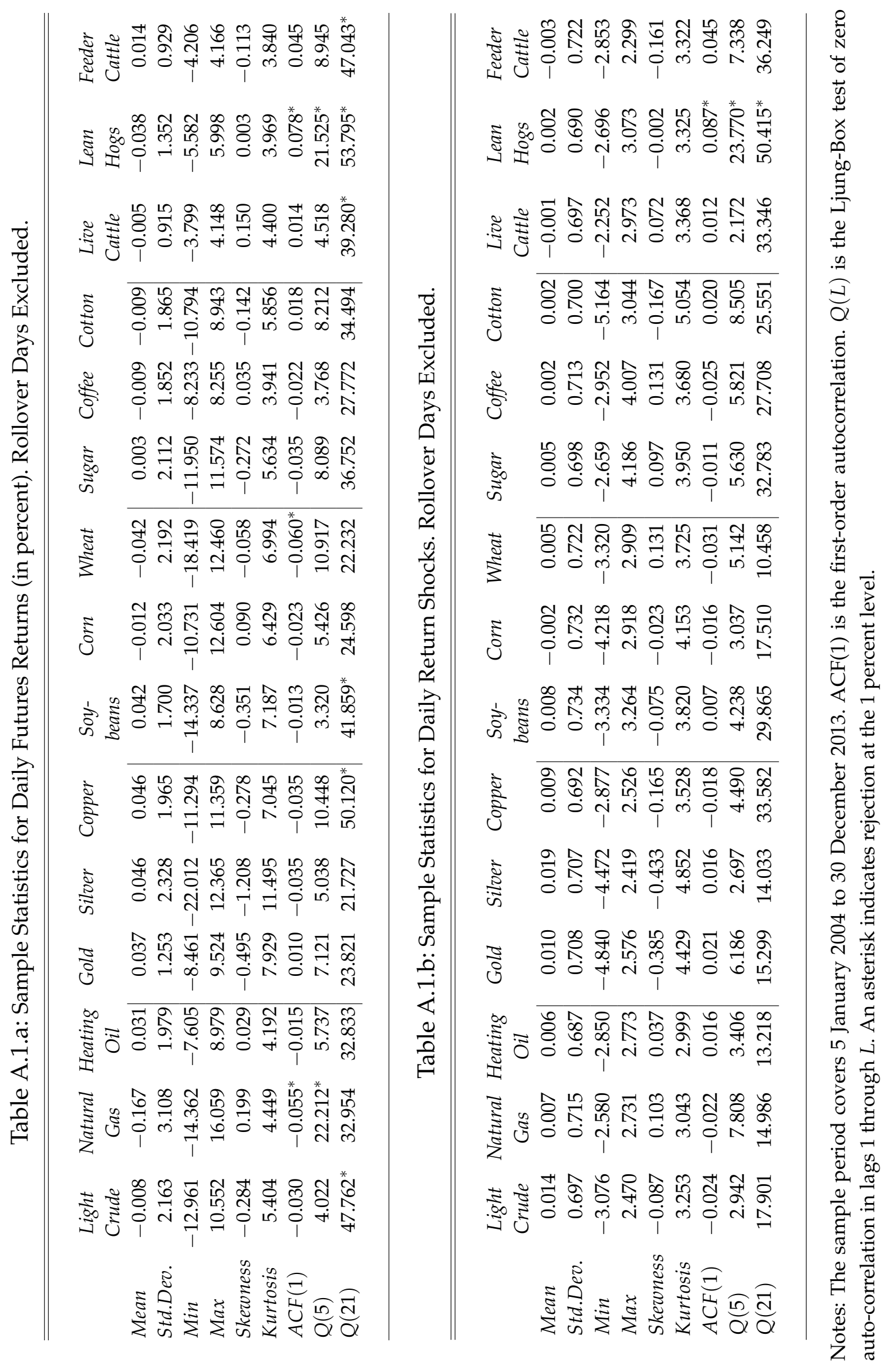




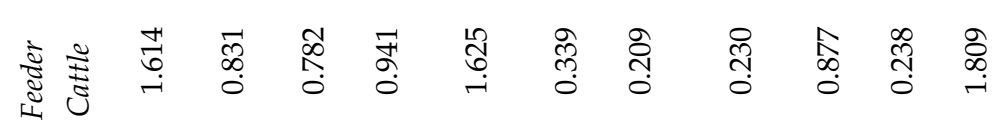

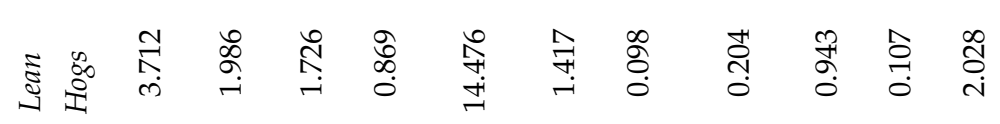

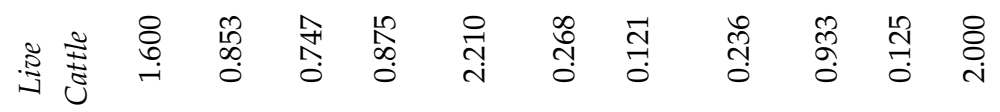

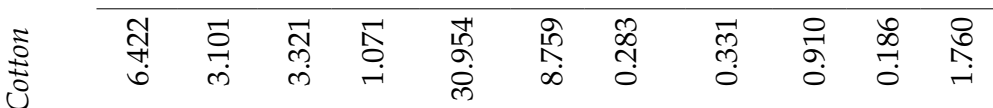

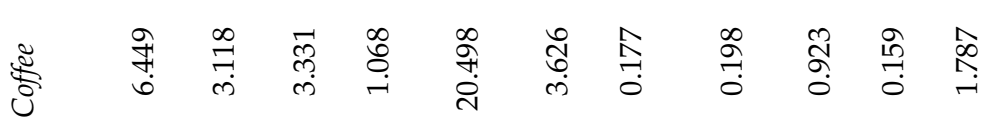

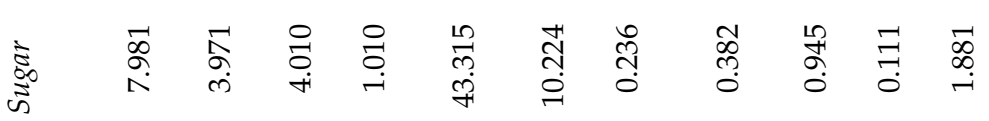

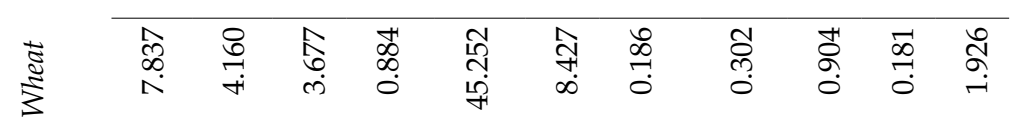

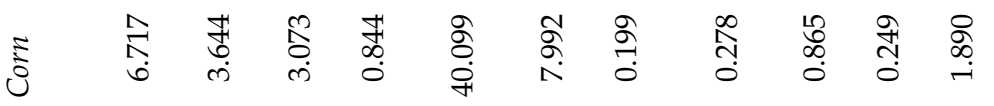

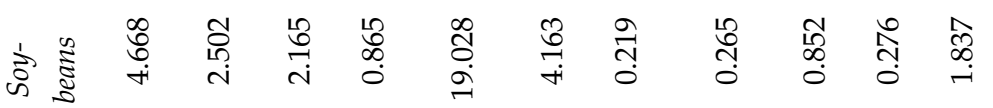

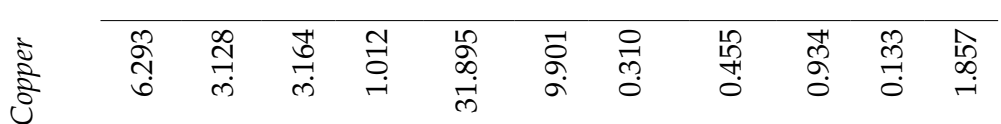

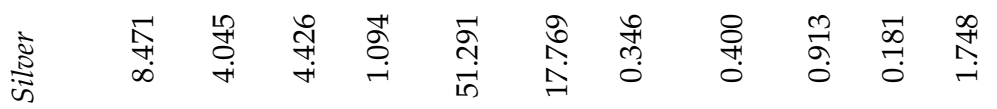

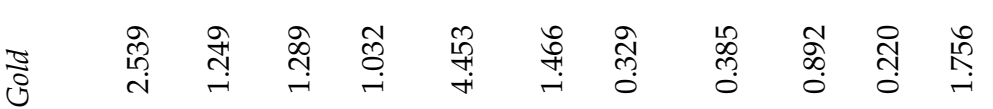

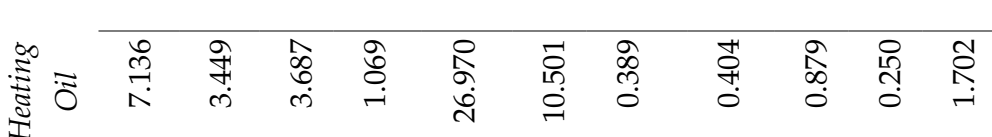

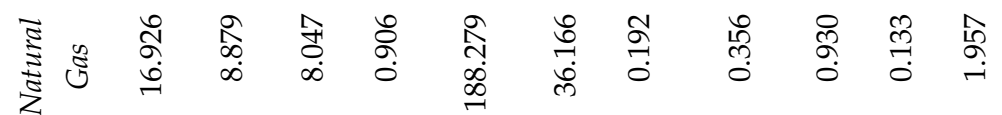

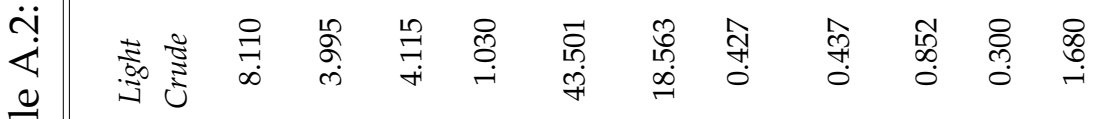
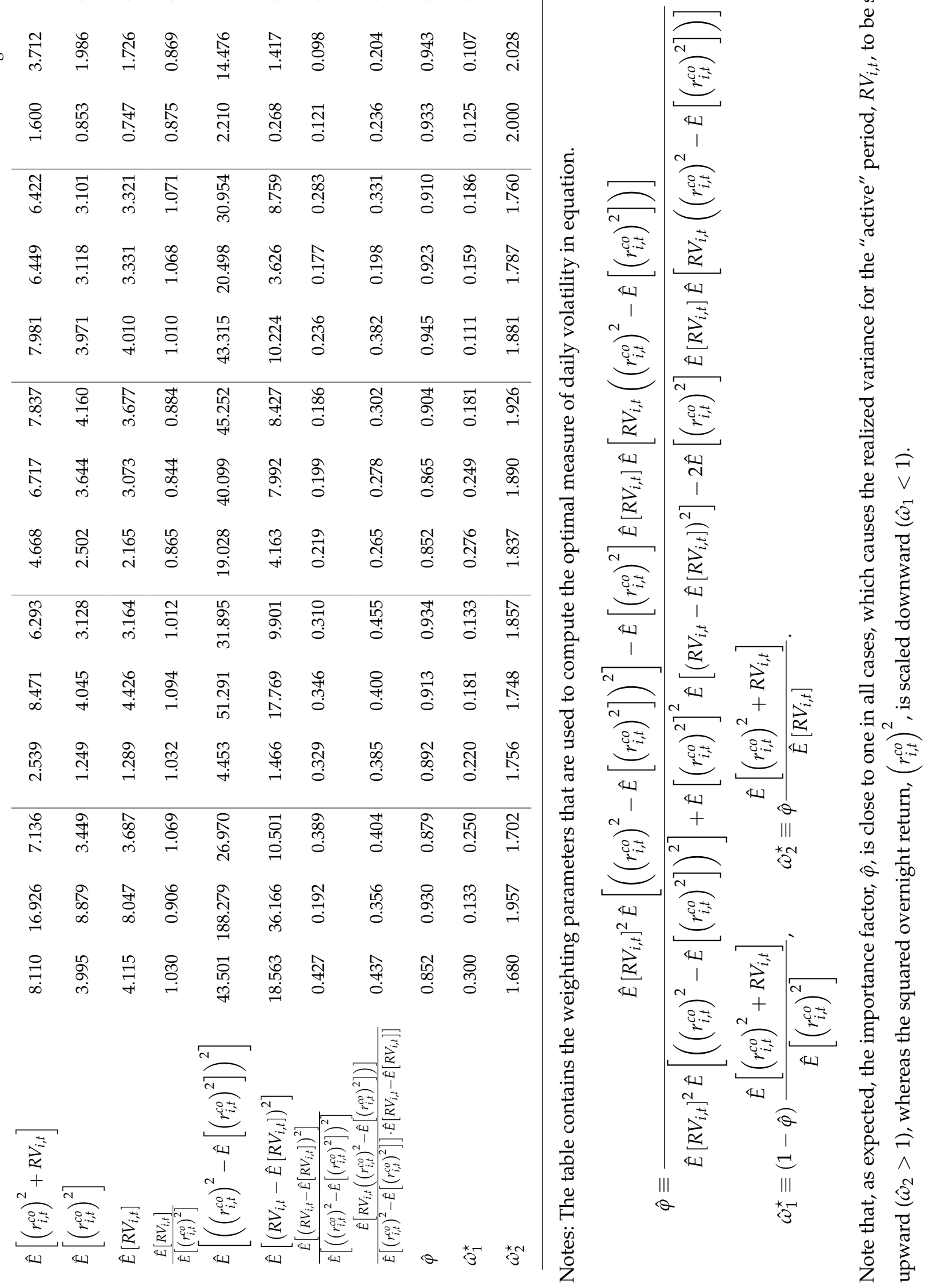


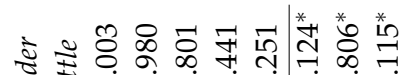

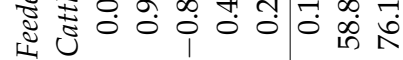

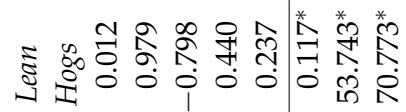

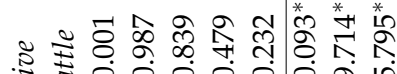

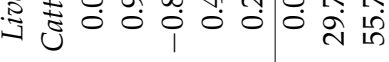

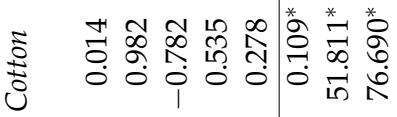
旁

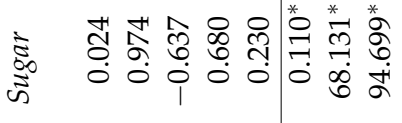

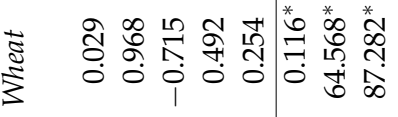

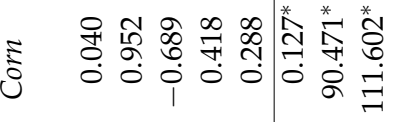

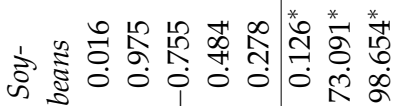

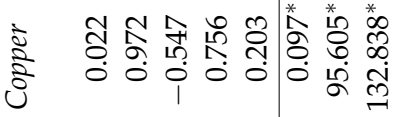

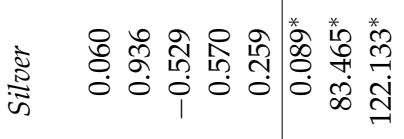

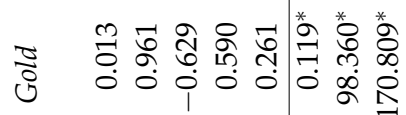

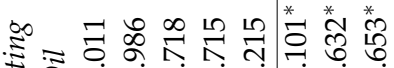

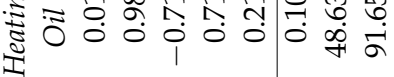

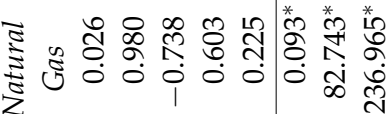

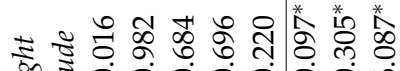

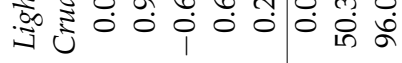

麘的可

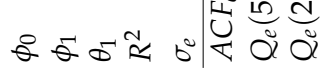

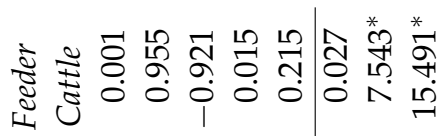

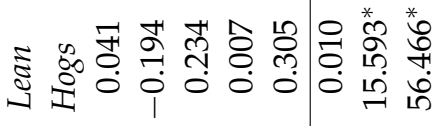

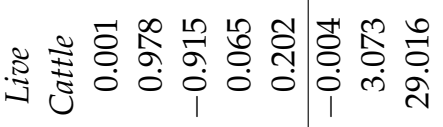

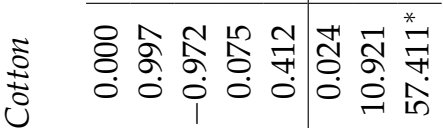

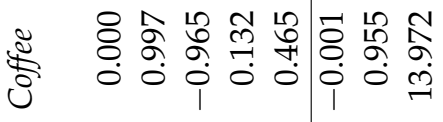

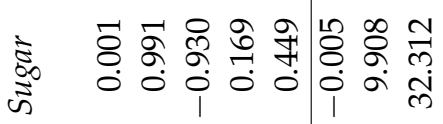

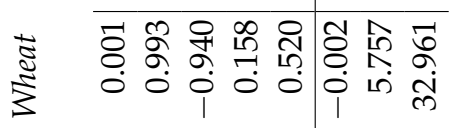

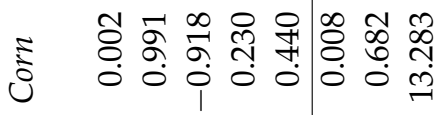

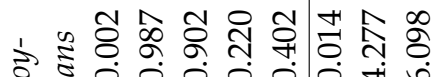
कि

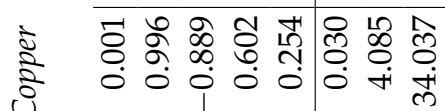

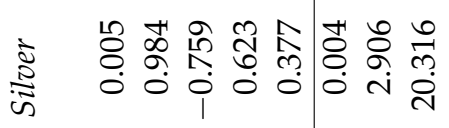

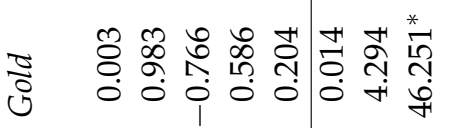

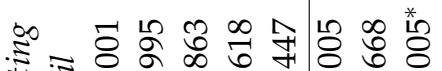

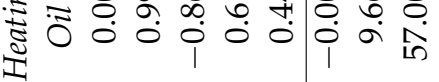

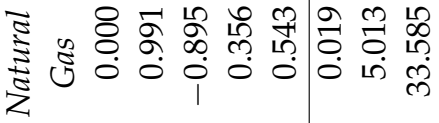

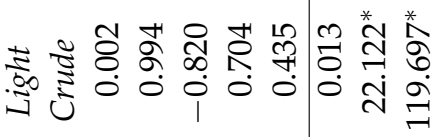

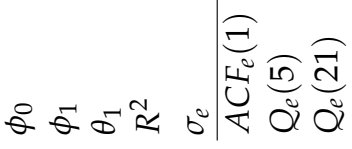

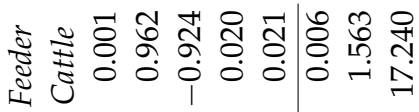

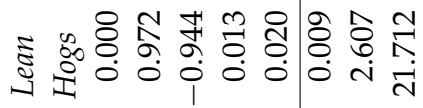

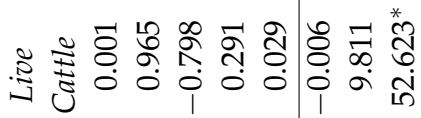

章

总

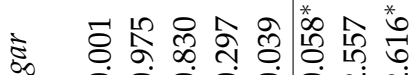

जิ

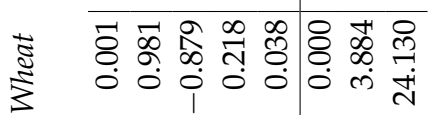

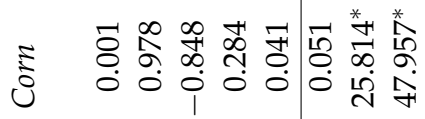

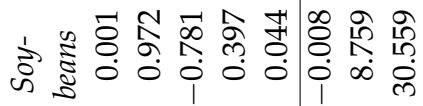

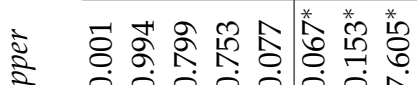

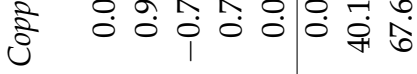

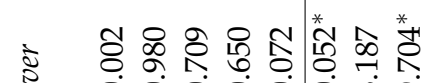

के ००

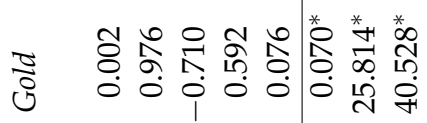

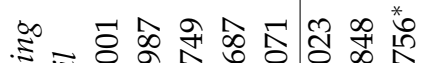

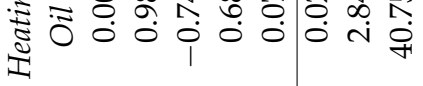

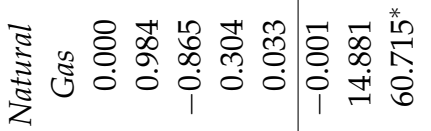

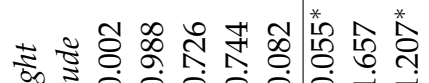

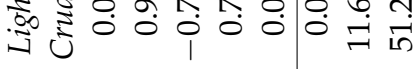

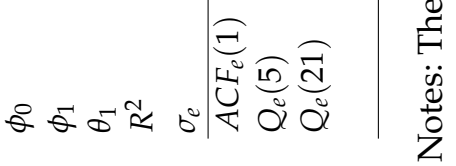


Table A.4: Intervals of Trading for 15 Commodities.

\begin{tabular}{|c|c|c|}
\hline Commodity & Period & Trading Interval(s) \\
\hline \multirow[t]{4}{*}{ Crude Oil, Natural Gas, and Heating Oil } & $5 / 1-2004$ to $9 / 6-2006$ & $00.00-14.30$ \\
\hline & & $15.15-12.00$ \\
\hline & $12 / 6-2006$ to $30 / 12-2013$ & $00.00-17.15$ \\
\hline & & $18.00-12.00$ \\
\hline \multirow[t]{6}{*}{ Gold, Silver } & $5 / 1-2004$ to $28 / 5-2004$ & $00.00-13.30$ \\
\hline & & $15.15-12.00$ \\
\hline & $1 / 6 / 2004$ to $1 / 12-2006$ & $00.00-13.30$ \\
\hline & & $14.00-12.00$ \\
\hline & $4 / 12-2006$ to $30 / 12-2013$ & $00.00-17.15$ \\
\hline & & $18.00-12.00$ \\
\hline \multirow{6}{*}{ Copper } & 5/1-2004 to $4 / 6-2004$ & $00.00-13.00$ \\
\hline & & $15.15-12.00$ \\
\hline & $7 / 6-2004$ to $1 / 12-2006$ & $00.00-13.00$ \\
\hline & & $14.00-12.00$ \\
\hline & $4 / 12-2006$ to $30 / 12-2013$ & $00.00-17.15$ \\
\hline & & $18.00-12.00$ \\
\hline \multirow{3}{*}{ Live Cattle, Lean Hogs, and Feeder Cattle } & $5 / 1-2004$ to $1 / 6-2007$ & $10.05-14.00$ \\
\hline & $4 / 6-2007$ to $30 / 12-2013$ & $00.00-17.00$ \\
\hline & & $18.00-12.00$ \\
\hline \multirow{17}{*}{ Corn, Soybeans, and Wheat } & $5 / 1-2004$ to $7 / 10-2005$ & $00.00-7.00$ \\
\hline & & $10.30-14.15$ \\
\hline & & $20.30-12.00$ \\
\hline & $10 / 10-2005$ to $11 / 1-2008$ & $00.00-7.00$ \\
\hline & & $10.30-14.15$ \\
\hline & & $19.30-12.00$ \\
\hline & $11 / 1-2008$ to $30 / 6-2009$ & $00.00-7.00$ \\
\hline & & $10.30-14.15$ \\
\hline & & $19.00-12.00$ \\
\hline & $1 / 7-2009$ to $18 / 5-2012$ & $00.00-8.15$ \\
\hline & & $10.30-14.15$ \\
\hline & & $19.00-12.00$ \\
\hline & $21 / 5-2012$ to $5 / 4-2013$ & $00.00-15.00$ \\
\hline & & $18.00-12.00$ \\
\hline & $8 / 4-2013$ to $30 / 12-2013$ & $00.00-8.45$ \\
\hline & & $9.30-14.15$ \\
\hline & & $20.00-12.00$ \\
\hline \multirow[t]{2}{*}{ Sugar } & 5/1-2004 to $1 / 2-2007$ & $9.00-00.00$ \\
\hline & $2 / 2-2007$ to $30 / 12-2013$ & $2.30-14.00^{*}$ \\
\hline \multirow[t]{2}{*}{ Coffee } & $5 / 1-2004$ to $1 / 2-2007$ & $9.15-12.30$ \\
\hline & $2 / 2-2007$ to $30 / 12-2013$ & $3.30-14.00^{*}$ \\
\hline \multirow[t]{4}{*}{ Cotton } & $5 / 1-2004$ to $1 / 2-2007$ & $10.30-14.15$ \\
\hline & $2 / 2-2007$ to $27 / 3-2009$ & $3.30-14.45$ \\
\hline & $30 / 3-2009$ to $30 / 12-2013$ & $00.00-14.30^{*}$ \\
\hline & & $21.00-12.00$ \\
\hline
\end{tabular}




\section{Research Papers \\ 2013}

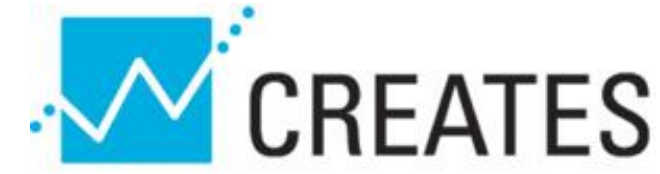

Center for Research in Econometric Analysis of Time Series

2014-15: $\quad$ Federico Carlini and Katarzyna Lasak: On an Estimation Method for an Alternative Fractionally Cointegrated Model

2014-16: Mogens Bladt, Samuel Finch and Michael Sørensen: Simulation of multivariate diffusion bridges

2014-17: $\quad$ Markku Lanne and Henri Nyberg: Generalized Forecast Error Variance Decomposition for Linear and Nonlinear Multivariate Models

2014-18: $\quad$ Dragan Tevdovski: Extreme negative coexceedances in South Eastern European stock markets

2014-19: $\quad$ Niels Haldrup and Robinson Kruse: Discriminating between fractional integration and spurious long memory

2014-20: $\quad$ Martyna Marczak and Tommaso Proietti: Outlier Detection in Structural Time Series Models: the Indicator Saturation Approach

2014-21: $\quad$ Mikkel Bennedsen, Asger Lunde and Mikko S. Pakkanen: Discretization of Lévy semistationary processes with application to estimation

2014-22: $\quad$ Giuseppe Cavaliere, Morten Ørregaard Nielsen and A.M. Robert Taylor: Bootstrap Score Tests for Fractional Integration in Heteroskedastic ARFIMA Models, with an Application to Price Dynamics in Commodity Spot and Futures Markets

2014-23: $\quad$ Maggie E. C. Jones, Morten Ørregaard Nielsen and Michael Ksawery Popiel: A fractionally cointegrated VAR analysis of economic voting and political support

2014-24: $\quad$ Sepideh Dolatabadim, Morten Ørregaard Nielsen and Ke Xu: A fractionally cointegrated VAR analysis of price discovery in commodity futures markets

2014-25: $\quad$ Matias D. Cattaneo and Michael Jansson: Bootstrapping Kernel-Based Semiparametric Estimators

2014-26: $\quad$ Markku Lanne, Jani Luoto and Henri Nyberg: Is the Quantity Theory of Money Useful in Forecasting U.S. Inflation?

2014-27: $\quad$ Massimiliano Caporin, Eduardo Rossi and Paolo Santucci de Magistris: Volatility jumps and their economic determinants

2014-28: $\quad$ Tom Engsted: Fama on bubbles

2014-29: $\quad$ Massimiliano Caporin, Eduardo Rossi and Paolo Santucci de Magistris: Chasing volatility - A persistent multiplicative error model with jumps

2014-30: $\quad$ Michael Creel and Dennis Kristensen: ABC of SV: Limited Information Likelihood Inference in Stochastic Volatility Jump-Diffusion Models

2014-31: $\quad$ Peter Christoffersen, Asger Lunde and Kasper V. Olesen: Factor Structure in Commodity Futures Return and Volatility 